Article

\title{
Sensitivity Analysis of the DART Model for Forest Mensuration with Airborne Laser Scanning
}

\author{
Osian Roberts ${ }^{1, *(\mathbb{D})}$, Pete Bunting ${ }^{1}{ }^{\mathbb{D}}$, Andy Hardy ${ }^{1} \mathbb{D}$ and Daniel McInerney ${ }^{2}$ \\ 1 Department of Geography and Earth Sciences, Aberystwyth University, Aberystwyth SY23 3DB, UK; \\ pete.bunting@aber.ac.uk (P.B.); ajh13@aber.ac.uk (A.H.) \\ 2 Coillte Teoranta, Castletroy, V94 C780 Limerick, Ireland; daniel.mcinerney@coillte.ie \\ * Correspondence: odr1@aber.ac.uk; Tel.: +44-(0)-1970-628-552
}

Received: 25 November 2019; Accepted: 7 January 2020; Published: 10 January 2020

\begin{abstract}
Airborne Laser Scanning (ALS) measurements are increasingly vital in forest management and national forest inventories. Despite the growing reliance on ALS data, comparatively little research has examined the sensitivity of ALS measurements to varying survey conditions over commercially important forests. This study investigated: (i) how accurately the Discrete Anisotropic Radiative Transfer (DART) model was able to replicate small-footprint ALS measurements collected over Irish conifer plantations, and (ii) how survey characteristics influenced the precision of discrete-return metrics. A variance-based global sensitivity analysis demonstrated that discrete-return height distributions were accurately and consistently simulated across 100 forest inventory plots with few perturbations induced by varying acquisition parameters or ground topography. In contrast, discrete return density, canopy cover and the proportion of multiple returns were sensitive to fluctuations in sensor altitude, scanning angle, pulse repetition frequency and pulse duration. Our findings corroborate previous studies indicating that discrete-return heights are robust to varying acquisition parameters and may be reliable predictors for the indirect retrieval of forest inventory measurements. However, canopy cover and density metrics are only comparable for ALS data collected under similar acquisition conditions, precluding their universal use across different ALS surveys. Our study demonstrates that DART is a robust model for simulating discrete-return measurements over structurally complex forests; however, the replication of foliage morphology, density and orientation are important considerations for radiative transfer simulations using synthetic trees with explicitly defined crown architectures.
\end{abstract}

Keywords: airborne laser scanning; forest inventory; radiative transfer modeling; sensitivity analysis

\section{Introduction}

Forest monitoring programs have been revolutionized by the growing availability and integration of remotely sensed data [1-3], with Airborne Laser Scanning (ALS) at the forefront of research in forest management and national forest inventories [4-7]. Numerous studies have now demonstrated that ALS height and density metrics (calculated at the stand or single-tree scale) are correlated with forest inventory measurements recorded at ground level. These include biometrics such as tree height [8-10], stem diameter [11,12], canopy cover and gap fraction [13,14], leaf-area index [15,16], timber volume $[17,18]$, biomass $[19,20]$ and carbon content $[21,22]$. Consequently, researchers and forest managers have increasingly used ALS measurements for the indirect retrieval of forest biometrics that are impractical to quantify directly through conventional forest mensuration techniques [23-27]. Forest inventory measurements derived from ALS data are often extrapolated to regional or national scales using covariates obtained from optical or radar satellite observations [28-30]. This multi-sensor upscaling approach facilitates the wall-to-wall retrieval of forest inventory biometrics through the 
integration of wide-area satellite observations, high-resolution ALS data and field measurements acquired from a representative sample of forests [31-34].

Today, most ALS sensors used in operational forestry are small-footprint $(<1 \mathrm{~m})$ pulsed laser systems capable of recording a finite number of discrete returns (typically <5) per laser pulse [35]. Since discrete-return instruments decompose the backscatter signal into a limited number of targets, they provide vestigial measurements of forest structure and are often insensitive to stem and understory components occluded by the forest canopy [36,37]. In contrast, waveform systems digitize the entire backscatter signal at high frequency, thereby recording more detailed information on forest structures residing within the laser footprint $[38,39]$. While waveform systems have become increasingly prevalent in recent years, ALS surveys undertaken for operational forestry primarily employ discrete-return metrics obtained through the Gaussian decomposition of ALS waveforms $[40,41]$. This may be due to the additional cost and complexity of processing waveform data [42], or in some cases, due to the marginal gains provided by full-waveform analysis [43-46].

Forest biometrics are derived from discrete-return measurements using two common methods, namely the area-based approach (ABA) $[6,47,48]$ and the single-tree approach [49-51]. In the ABA, ALS measurements are spatially gridded and converted into a range of structural measures (height percentiles and density statistics) that quantify the vertical and horizontal distribution of laser returns within the forest canopy [52-55]. Discrete-return statistics are then regressed against forest inventory measurements recorded at ground level in fixed-area plots [56-59]. While the ABA facilitates the indirect retrieval of forest inventory measurements with relatively inexpensive low-density ALS data [60-62], the method explicitly assumes that variations in the distribution of laser returns are directly related to forest structural properties (e.g., tree height, crown morphology, foliage density), when in fact, discrete-return distributions are also influenced by variations in sensor configuration, viewing geometry and ground topography [63-65]. Such variations can impact the derivation of forest biometrics, causing errors of $\pm 10 \%$ for timber volume retrieval when predictive models are not reconstructed or refitted for different ALS surveys [66,67].

Previous studies have examined the influence of acquisition parameters on the precision of ALS measurements through repeat surveys undertaken over individual research sites [68-71]. Several such investigations have demonstrated that discrete-return metrics are influenced significantly by variations in platform altitude, scanning angle and pulse repetition frequency $[66,67,72,73]$. Higher pulse repetition frequencies are associated with a reduction in pulse energy that decreases pulse penetration $[74,75]$ and the proportion of multiple canopy returns [66,73]. Conversely, lower pulse frequencies and increased platform altitude are associated with a reduction in pulse density that results in canopy height underestimation as: (i) fewer returns are recorded directly at treetops [63,76,77], and (ii) fewer ground returns are acquired for the interpolation of digital terrain models with accurate microtopography $[73,78,79]$. The influence of pulse density has also been tested empirically with different sensors $[74,80,81]$ and through the artificial decimation of discrete returns $[61,82,83]$. Several studies have established that low-density ALS data $\left(0.5-2\right.$ pulses $\left.\mathrm{m}^{2}\right)$ are sufficient to obtain reliable height and density metrics for the retrieval of most forest inventory parameters [60,62]. However, forest biometrics such as canopy cover, gap fraction and leaf-area index are often measured less precisely due to their greater sensitivity to variations in discrete-return density $[61,84]$ and laser scanning angle $[85,86]$.

While empirical studies can provide valuable insights into the impact of survey characteristics on the precision of ALS measurements, repeat surveys do not offer ideal experimental conditions due to: (i) the anisotropy of ALS backscatter arising from variations in sensor position and viewing geometry, and (ii) sensor-specific characteristics (e.g., triggering mechanism, scanning pattern, laser beam profile) that complicate the task of isolating the effects of individual acquisition parameters. An alternative approach involves the testing of acquisition parameters through radiative transfer simulations where ALS surveys are replicated in controlled experiments over computer-generated forests $[65,87,88]$. Radiative transfer simulations provide a cost-effective alternative to repeat ALS surveys, while allowing 
a greater variety of acquisition parameters to be tested systematically across a broader range of forests than can be achieved through direct measurements [89]. Moreover, the information gleaned through the physical modeling of ALS data can enhance our understanding of how laser pulses interact with forest canopies [90-93], enabling the retrieval of forest biometrics through radiative transfer inversion techniques without requiring exhaustive field measurements needed for empirically derived predictive models [14,94-97]. Despite these advantages, the task of replicating forest canopies in radiative transfer models remains an active area of research due to challenges associated with: (i) reproducing individual tree locations, (ii) generating synthetic trees with realistic structure and allometric properties, and (iii) selecting crown archetypes that adequately represent forest canopy structure and reflectance characteristics [98-102].

While several simulation studies have examined the impact of sensor and survey design on large-footprint ( $\geq 3 \mathrm{~m}$ ) waveform LiDAR (Light Detection and Ranging) acquisitions [93,94,97,103-105], fewer investigations have examined small-footprint discrete-return measurements due to the computational demands of simulating multi-pulse ALS acquisitions over complex landscapes [65,96,106-108]. In previous studies, the influence of survey characteristics on ALS measurements has been tested through local sensitivity analyses, where only one acquisition parameter was varied at a time while the remaining parameters were held constant at nominal values $[65,87,88,109,110]$. Unfortunately, one-at-a-time methods are only appropriate for additive or linear models since they: (i) inadequately sample the parameter feature-space, and (ii) are unable to account for non-linear interactions between the simulation parameters [111-113]. In addition, forest canopies are often represented using turbid layers or geometric primitives (conical and ellipsoidal objects comprised of turbid media) as proxies for individual tree crowns [94,106-108,114-117]. While the use of abstract forest canopies can produce accurate simulations in certain forests [118,119], recent research demonstrates that simple crown archetypes can introduce large inaccuracies when simulating reflectance over structurally diverse forests due to the inadequate replication of twig and foliage morphology, density and orientation [98,100,120-122]. These findings indicate that more detailed three-dimensional representations of individual trees, e.g., [102,123,124] are required for realistic radiative transfer simulations over heterogeneous forests.

In the present study, we attempt to avoid a perfunctory sensitivity analysis [111,113] of the Discrete Anisotropic Radiative Transfer (DART) model by: (i) simulating ALS acquisitions over synthetic forests with explicitly defined crown architectures, and (ii) performing a variance-based sensitivity analysis in which all survey parameters are modulated systematically to identify factors influencing the accuracy and precision (repeatability) of discrete-return metrics [125,126]. Our investigation focuses exclusively on the simulation of small-footprint discrete-return ALS data due to its widespread use in operational forestry and its growing availability following the deployment of discrete-return sensors onboard unmanned aerial vehicles [127,128]. The aims of this study are to: (i) investigate whether a radiative transfer model can accurately replicate discrete-return measurements collected over commercial forests in the Republic of Ireland, and (ii) explore how survey and model parameters influence the precision of discrete-return metrics simulated over structurally diverse forests.

\section{The Discrete Anisotropic Radiative Transfer (DART) Model}

Radiative transfer in forested environments can be simulated with semi-empirical analytical models [129-131], Geometric Optical (GO) models [132-134] or radiative transfer models where the propagation of electromagnetic radiation is replicated through physically based mechanisms that govern photon interception, scattering and transmittance $[88,135]$. Analytical radiative transfer models commonly employ closed-form mathematical functions to replicate canopy reflectance measurements obtained from field or laboratory experiments, consequently their application is often limited by: (i) simplified representations of radiative transfer mechanisms, (ii) a lack of generality in their empirical parameterization, and (iii) an inability to simulate heterogeneous forests with complex ground topography $[89,136,137]$. A more detailed, flexible and transferable approach to radiative transfer 
modeling can be achieved through ray-tracing experiments where photon trajectories are simulated through Successive Orders of Scattering [138], radiosity methods [139,140], discrete ordinates [141,142] or Monte Carlo techniques [89]. Monte Carlo ray-tracing methods provide a tractable solution to radiative transfer modeling in forest canopies where photon scattering is stochastic, requiring that photon trajectories be repeatedly sampled in order to characterize bi-directional reflectance across different sensor viewing geometries and operating wavelengths. Monte Carlo methods have gained in popularity and complexity due to the recent proliferation of computer resources, with several models designed to simulate radiative transfer in one-dimensional canopies (e.g., 4SAIL [143], 5-Scale [144,145]) and three-dimensional forests (e.g., FLIGHT [87,146], Raytran [114], librat [147,148], FLiES [149]).

Three-dimensional radiative transfer models are required when path length is explicitly simulated for ALS acquisitions or radar interferometry [150]. DART is a three-dimensional model designed to simulate the propagation of electromagnetic radiation through heterogeneous terrestrial landscapes while accounting for variations in solar irradiance, atmospheric composition and sensor viewing geometry [137,151-153]. DART simulations of vegetation reflectance in the visible and near-infrared wavelengths have been used for the inversion of vegetation biometrics [154-160] and for reproducing imagery acquired from satellite and airborne sensors [161-163]. DART simulations have also been validated against field measurements [164] and compared against several independent reflectance models in the Radiation transfer Model Intercomparison (RAMI) experiments [165-169]. Although DART has been tested extensively in the passive optical domain, its ability to simulate small-footprint ALS data has received less attention, e.g., [170,171], with previous work focusing on terrestrial laser scanning [172] and large-footprint waveform LiDAR [173-175]. However, recent improvements to DART have facilitated the efficient simulation of multi-pulse acquisitions [137,176] with the ability to export ALS waveforms into the Sorted Pulse Data (SPD) format [177].

DART simulates the propagation of laser pulses in terrestrial landscapes using a forward Monte Carlo ray-tracing framework where pulse trajectories are tracked from the sensor using physically based mechanisms that govern photon interception, scattering and thermal emission $[137,178]$. To facilitate rapid and computationally efficient simulations, DART employs an Iterative Uniform Squared Discretization (IUSD) scheme to constrain pulse tracking to a finite number of pre-defined discrete scattering directions $\left(\Omega_{D}\right)$ that evenly sample the bi-directional reflectance distribution $[179,180]$. This pulse tracking framework greatly accelerates DART simulations as probable pulse trajectories can be determined from pre-computed scattering matrices using the box method [173]. However, this simplified scattering framework is susceptible to discretization error [181,182] if reflectance is anisotropic and the number of pre-defined angular directions are too few to accurately characterize the bi-directional reflectance distribution [178]. Such errors are negated by specifying many pre-defined scattering directions to produce a finer sampling of bi-directional reflectance at each scattering event [180].

DART can simulate terrestrial landscapes at varying levels of complexity depending on: (i) the level of detail required when replicating remote sensing measurements, and (ii) the computational resources available for performing ray-tracing simulations. Terrestrial landscapes are simulated in a voxel matrix where forest canopy components (stems, branches, foliage) are represented as triangular surfaces, turbid media or a combination of both. Turbid media voxels provide a simple representation of plant biomass, comprising of small planar surfaces with uniform density, angular distribution and reflectance properties. Conversely, for complex scenes where the position and geometry of forest canopy components are explicitly defined, DART voxels are comprised of triangles and parallelograms with discrete reflectance and transmittance characteristics [137,178]. In this latter mode of operation, DART can replicate structurally complex forests through the direct importation of 3D trees generated in external modeling software [183,184] or trees digitized from terrestrial laser scanning measurements [124,185]. Recent work by Roberts et al. [186] and Janoutová et al. [187] suggests that forest biometrics may be reliably inverted using simplified trees with foliage represented by turbid media. However, in the present study, we seek to minimize geometric assumptions 
associated with simplified crowns, therefore ALS acquisitions are simulated using trees with explicitly defined crown geometries and reflectance characteristics. We anticipate that trees with detailed crown architectures will enable more accurate ALS simulations at the scale of individual forest inventory plots, thereby permitting a robust sensitivity analysis of the DART model to variations in sensor and survey characteristics.

\section{Materials and Methods}

\subsection{Reference Data}

To calibrate our DART simulations, an ALS survey was acquired over 27,000 hectares of Sitka spruce (Picea sitchensis) and Lodgepole pine (Pinus contorta) plantations in the west of Ireland (Figure 1). These forests were selected due to their structural heterogeneity, with some compartments consisting of unthinned juvenile stands, while other compartments contained mature first-rotation crops having undergone several thinning treatments. The ALS survey was undertaken in February 2015 with a RIEGL LMS-Q680i sensor onboard a Pilatus PC6 aircraft flying at a nominal altitude of $550 \mathrm{~m}$ and a mean velocity of $204 \pm 5 \mathrm{kph}$. 116 flight lines were flown with a $40 \%$ overlap, a pulse repetition frequency of $360 \mathrm{kHz}$ and a maximum scanning angle of $30^{\circ}$ from nadir (60 swath), producing a mean point density of $29 \pm 10$ returns $\mathrm{m}^{2}$. The ALS data was processed with SPDLib [188] for the purpose of ground classification, the calculation of normalized heights and the production of area-based discrete-return metrics at $20 \mathrm{~m}$ resolution (cell size $=400 \mathrm{~m}^{2}$ ) throughout the study region. Ground classification followed a two-stage procedure where an initial ground surface was derived through a progressive morphology filter [189] and ground returns were then refined using a multi-scale curvature algorithm [190]. Normalized vegetation heights were calculated from ground surface elevation interpolated using the natural neighbor algorithm [191].

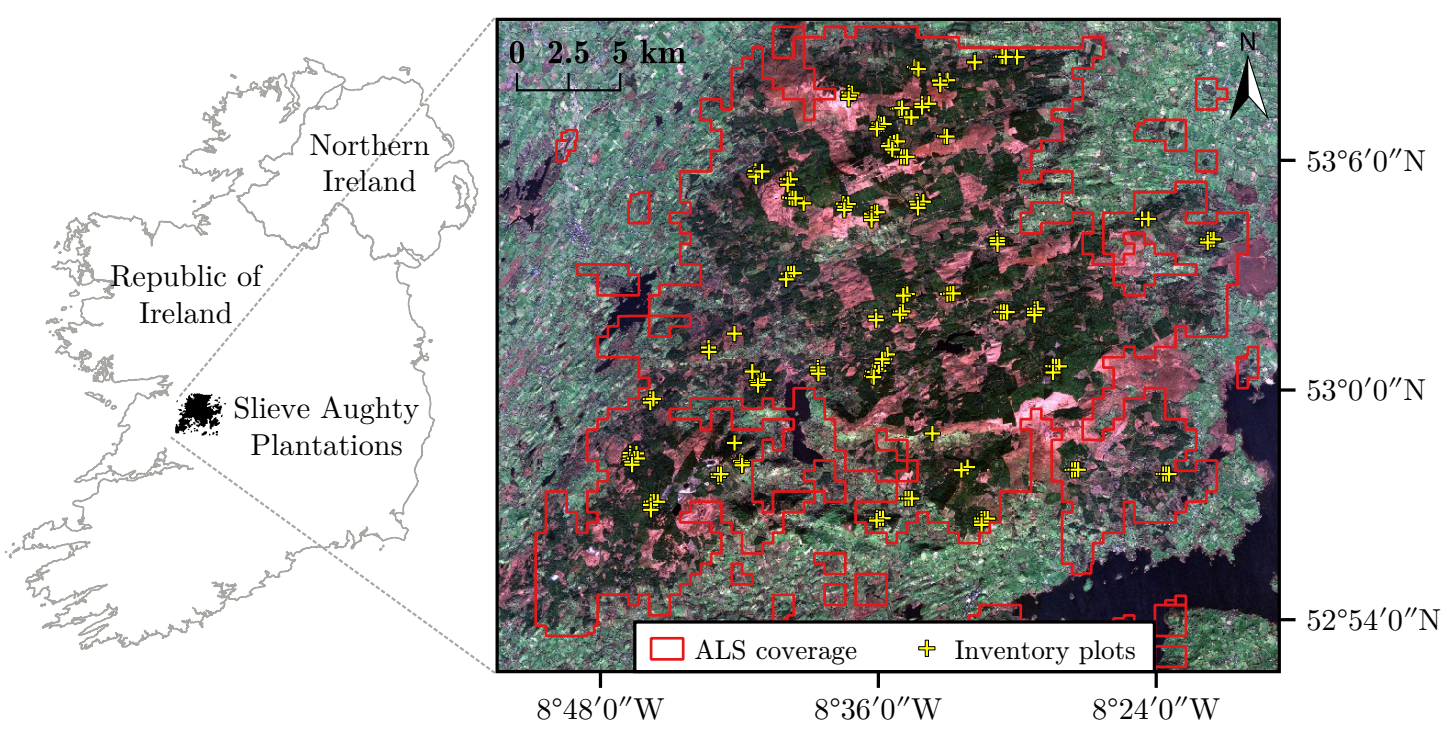

Figure 1. ALS data coverage and the location of forest inventory plots in the Slieve Aughty plantations, Republic of Ireland.

To accompany the ALS survey, Coillte Teoranta (Irish State Forestry Board) surveyors undertook a forest inventory campaign, collecting 170 fixed-area $\left(400 \mathrm{~m}^{2}\right)$ plots distributed throughout the study region (Figure 1). Plot centroids were geo-referenced with a differential GNSS receiver and the diameter of each tree was measured at breast height with digital calipers. Within each fixed-area plot, five tree height measurements were collected with a Vertex IV clinometer (www.haglofcg.com) for trees corresponding to the minimum, mean, maximum, 25th and 75th percentiles of the stem diameter distribution for the dominant tree species. Height measurements were also collected for non-dominant 
tree species (e.g., Larix kaempferi, Pseudotsuga menziesii, Betula pendula), producing DBH and height measurements for a total of 1232 trees. The forest inventory revealed structural heterogeneity in the plantations, with stocking densities of 525-2375 trees ha ${ }^{-1}$, basal area varying between 6 and $82 \mathrm{~m}^{2} \mathrm{ha}^{-1}$ and tree heights ranging from 2.5-30.9 $\mathrm{m}$ (Table 1).

Table 1. Summary statistics for forest inventory measurements recorded in 170 fixed-area $\left(400 \mathrm{~m}^{2}\right)$ plots distributed throughout the Slieve Aughty plantations.

\begin{tabular}{lccccccc}
\hline Biometric & Min & Max & Mean & SD & IQR & CV & Skewness \\
\hline Basal area $\left(\mathrm{m}^{2} \mathrm{ha}^{-1}\right)$ & 6.4 & 82.2 & 32.7 & 13.2 & 16.2 & 0.40 & 0.81 \\
DBH $(\mathrm{cm})$ & 2.0 & 71.2 & 19.6 & 10.7 & 14.1 & 0.55 & 0.91 \\
Tree Density $\left(\mathrm{stems} \mathrm{ha}^{-1}\right)$ & 525 & 2375 & 1238 & 417 & 675 & 0.34 & 0.09 \\
Tree Height $(\mathrm{m})$ & 2.5 & 30.9 & 15.2 & 6.3 & 9.7 & 0.41 & 0.05 \\
\hline
\end{tabular}

Note: $\mathrm{SD}$ = standard deviation; IQR = inter-quartile range; $\mathrm{CV}=$ coefficient of variation.

\subsection{Forest Plot Reconstruction}

Allometric relationships were derived from the single-tree measurements to facilitate the creation of 700 computer-generated trees using the OnyxTree modeling software [192]. A diverse range of trees were generated with heights ranging from 3 to $30 \mathrm{~m}$, DBH values of 3-73 cm and crown diameters of 1.2-8.6 m. Each simulated tree was comprised of a single stem connected to a series of boughs, branches, twigs and needles. However, the position, length and orientation of each component was randomly varied to ensure that each tree was structurally unique. Needles were simulated as rectangular planar surfaces (Figure 2c) with a length of $30 \mathrm{~mm} \pm 15 \%$ and inclined at $75-90^{\circ}$ from each twig to replicate the erectophile needle orientation prevalent in Sitka spruce [193]. Stem profiles were modeled using a taper function developed for Sitka spruce plantations in Northern Britain:

$$
d=0.9297 d b h(1-z)^{[0.7784+-0.6145(1-z)]}(1+0.4622 \exp (-24.7307 z))
$$

where $z$ represents the stem height as a fraction of top height, $d b h$ is the tree diameter at breast height and $d$ denotes the estimated tree diameter at height $z$ [194]. To accelerate the DART simulations, tree components were organized into three structural groups (stems, branches and needles) and Lambertian reflectance properties were assigned to each group based on field spectroradiometer measurements collected over the 350-2500 nm spectral range.

100 fixed-area $\left(400 \mathrm{~m}^{2}\right)$ plots from the forest inventory campaign were selected for reconstruction based on a maximin Latin hypercube sampling strategy which ensured that the reconstructed plots were sampled throughout the multidimensional distribution of the forest inventory attributes [195-197]. Individual tree positions and biophysical attributes (e.g., height, DBH, crown diameter) were then estimated through Monte Carlo simulations that sought to minimize differences between the simulated and observed plot biometrics in terms of tree density, basal area and the minimum, mean and maximum values for $\mathrm{DBH}$ and tree height. This statistical approach was necessary because: (i) individual tree locations were not recorded in the forest inventory, and (ii) tree detection methods (e.g., watershed segmentation, local maxima and region-growing [198,199], point-cloud segmentation [200,201] and manual digitizing) were unsuccessful in delineating individual trees with sufficient accuracy due to the presence of overlapping crowns and suppressed trees. The synthetic trees were positioned at regular intervals along parallel rows to replicate the planting patterns and stocking densities found in the Slieve Aughty plantations (Figure 2a,b). A random offset was applied to each tree position to prevent perfectly straight planting rows, and realistic ground topography was incorporated by importing digital terrain models from the reference ALS survey. To replicate edge-effects caused by nearby trees protruding into the forest plot, each fixed-area plot was positioned within a $900 \mathrm{~m}^{2}$ DART scene with additional trees located around the plot perimeter. Following each DART simulation, the ALS data was subset to the central $400 \mathrm{~m}^{2}$ plot by discarding laser returns recorded outside of the plot boundary. 
(a)

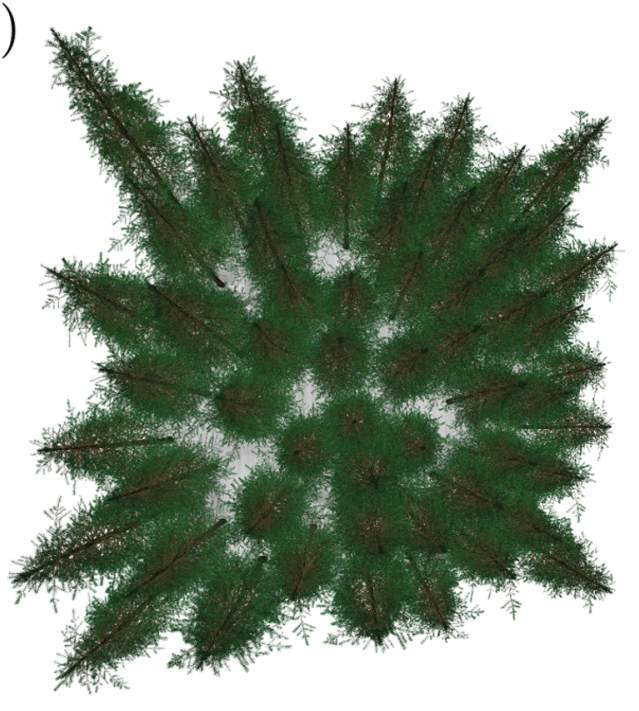

(b)

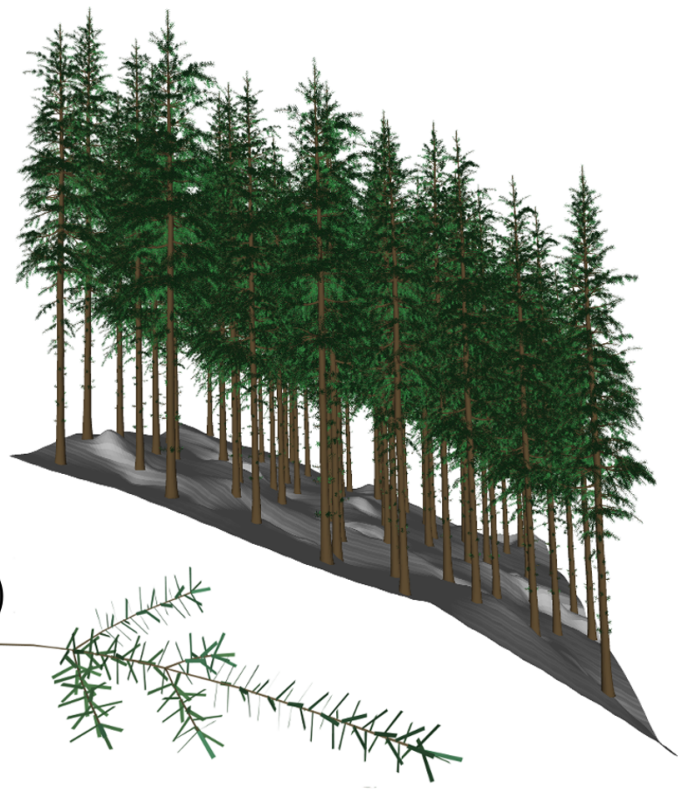

Figure 2. RGB renderings from aerial (a) and horizontal (b) perspectives of a reconstructed forest inventory plot imported into the DART model. Needles were modeled as rectangular surfaces inclined at $75-90^{\circ}$ from each twig (c).

\subsection{DART Simulation Parameters}

DART (version 5.7.3) simulations were performed in multi-pulse mode using finite scenes where pulses were discarded once they had exited the simulation boundary [176]. To mimic acquisition parameters used in the reference ALS survey, we restricted laser scanning angles to $\leq 30^{\circ}$ from nadir $\left(60^{\circ}\right.$ swath) and we maintained a constant laser operating wavelength of $1550 \mathrm{~nm}$ to replicate the Erbium-doped fiber laser onboard the RIEGL LMS-Q680i sensor. Following [75], laser beam divergence was modulated between $0.3-0.8 \mathrm{mrad}$ to investigate the impact of spreading pulse energy across variable-sized (0.12-1.2 m) laser footprints. To replicate the work of Yu et al. [77] and Takahashi et al. [78], platform altitude was varied from 400-1500 m. Pulse repetition frequency (PRF) was adjusted from 100-400 kHz, while the scan rate was modulated between 50-200 Hz. These parameter ranges were consistent with the RIEGL LMS-Q680i sensor specifications [202], producing pulse densities (8-30 pulses $\mathrm{m}^{2}$ ) consistently higher than for ALS acquisitions in Scandinavia where sparse data $\left(0.5-2\right.$ pulses $\left.\mathrm{m}^{2}\right)$ are often used for area-based forest inventory [66,67].

Several of the DART model parameters (Table 2) were modulated to investigate their influence on discrete-return metrics. The number of pre-defined discrete scattering directions $\left(\Omega_{D}\right)$ was varied from 60-200, while the voxel resolution was adjusted between 0.1 and $1.0 \mathrm{~m}$. We expected these two simulation parameters to have a negligible impact on the discrete-return metrics due to the avoidance of turbid media [203]; however we chose to vary these parameters as a sanity check. Each simulated pulse was tracked until its energy fell below a propagation threshold of $5-15 \%$ of mean pulse energy, while the discretization interval for digitizing each received waveform (acquisition rate) was varied between 0.5 and $3 \mathrm{~ns}$. The minimum number of simulated photons fired into each DART cell (sub-center photons) was adjusted between 1 and 15 to examine the impact of increasing the number of Monte Carlo iterations performed for simulating photon scattering trajectories within each voxel. The scattering order, controlling the maximum number of scattering events that each simulated photon can undergo, was also modulated between 5 and 15 . 
Table 2. Parameter bounds for simulating ALS data in DART.

\begin{tabular}{|c|c|c|}
\hline Name & Definition & Range \\
\hline \multicolumn{3}{|c|}{ Sensor parameters } \\
\hline Aircraft velocity & Aircraft flying velocity. & $40-70 \mathrm{~m} / \mathrm{s}$ \\
\hline Beam divergence & Radius of emitted laser beam. & $0.3-0.8 \mathrm{mrad}$ \\
\hline Gaussian sigma $\left(\sigma_{\beta}\right)$ & $\begin{array}{l}\text { Standard deviation of the point spread function for } \\
\text { laser pulse energy. }\end{array}$ & $0.2-0.5$ \\
\hline Half-pulse duration & $\begin{array}{l}\text { Laser pulse temporal duration at full-width } \\
\text { half-maximum. }\end{array}$ & $3.5-5.5 \mathrm{~ns}$ \\
\hline Pulse repetition frequency & Frequency of emitted laser pulses per second. & $100-400 \mathrm{kHz}$ \\
\hline Scan angle & Maximum laser scanning half-angle from nadir. & $10-30^{\circ}$ \\
\hline Scan rate & Number of parallel scan lines per second. & $50-200 \mathrm{~Hz}$ \\
\hline Sensor altitude & Platform altitude above ground level. & $400-1500 \mathrm{~m}$ \\
\hline Wavelength & Laser operating wavelength. & $1550 \mathrm{~nm}$ \\
\hline \multicolumn{3}{|c|}{ DART parameters } \\
\hline Acquisition rate & $\begin{array}{l}\text { Temporal interval for digitizing received } \\
\text { pulse energy. }\end{array}$ & $0.5-3 \mathrm{~ns}$ \\
\hline Propagation threshold & $\begin{array}{l}\text { Minimum pulse energy threshold. Pulse tracking } \\
\text { ends when energy } \leq \text { propagation threshold } \times \\
\text { mean pulse energy. }\end{array}$ & $0.05-0.15$ \\
\hline Scattering directions $\left(\Omega_{D}\right)$ & $\begin{array}{l}\text { Number of angular directions used to discretize } \\
\text { photon scattering [180]. }\end{array}$ & $60-200$ \\
\hline Scattering order & $\begin{array}{l}\text { Maximum number of scattering events simulated } \\
\text { per pulse. }\end{array}$ & $5-15$ \\
\hline Sub-center photons & $\begin{array}{l}\text { Minimum number of rays simulated per sub-cell } \\
\text { in each voxel. }\end{array}$ & $1-15$ \\
\hline Voxel size & Resolution of voxels constituting the DART scene. & $0.1-1.0 \mathrm{~m}$ \\
\hline \multicolumn{3}{|c|}{ Topography } \\
\hline Slope gradient & Percentage hillslope gradient. & $10-75 \%$ \\
\hline
\end{tabular}

Laser pulses were fired along parallel scan lines to replicate the scanning pattern produced by the rotating polygon mirror onboard the RIEGL LMS-Q680i sensor [204]. Equations for generating realistic pulse distributions were obtained from Wehr and Lohr [205] and Baltsavias [206]. The along-track pulse spacing $\left(d x_{\text {along }}\right)$ was calculated following:

$$
d x_{\text {along }}=\frac{v}{f_{s c}}
$$

where $v$ is the sensor flying velocity $(\mathrm{m} / \mathrm{s})$ and $f_{s c}$ is the scan rate measured in hertz or horizontal scan lines per second. The number of pulses per scan line $\left(N_{\text {pulses }}\right)$ was then determined:

$$
N_{\text {pulses }}=\frac{P R F}{f_{s c}}
$$

where $P R F$ denotes the pulse repetition frequency in hertz. The swath width was subsequently calculated as:

$$
\text { Swath Width }(m)=2 h \cdot \tan \left(\frac{\theta}{2}\right)
$$

where $h$ denotes the sensor altitude in meters and $\theta$ represents the maximum scanning half-angle in radians. Finally, the across-track pulse spacing $\left(d x_{a c r o s s}\right)$ was determined:

$$
d x_{\text {across }}=\frac{\text { Swath Width }}{N_{\text {pulses }}}
$$


thereby enabling pulses to be positioned at regular intervals (i.e., consistent across-track spacing) across each scan line.

Based on the empirical observations of Armston [207], peak pulse power $\left(A_{\text {peak }}\right)$ was varied as a function of pulse repetition frequency $(\mathrm{kHz})$ :

$$
A_{\text {peak }}(m J)=1.0941 \cdot P R F^{-1}
$$

and the temporal profile of each laser pulse was simulated using a centered super-Gaussian distribution:

$$
E_{\text {pulse }}=A_{\text {peak }} \cdot \exp \left(-\left(\frac{t^{2}}{2 \sigma_{t}^{2}}\right)\right)
$$

where $t$ denotes the elapsed time in ns and $\sigma_{t}$ represents the time at which pulse intensity reaches $50 \%$ of peak amplitude (Figure 3). We chose to vary the pulse duration at full-width half-maximum between 3.5 and $5.5 \mathrm{~ns}$ to investigate the impact of longer pulse durations on the accuracy and precision of the ALS metrics. These parameter bounds were consistent with experiments of Armston [207] in which 10,000 transmitted pulses were recorded from the RIEGL LMS-Q680i sensor with a mean full-width half-maximum of $4.55 \pm 0.016$ ns. Similarly, Jalobeanu and Gonçalves [204] observed Gaussian pulses with a mean half-pulse duration of $4.3 \mathrm{~ns}$.

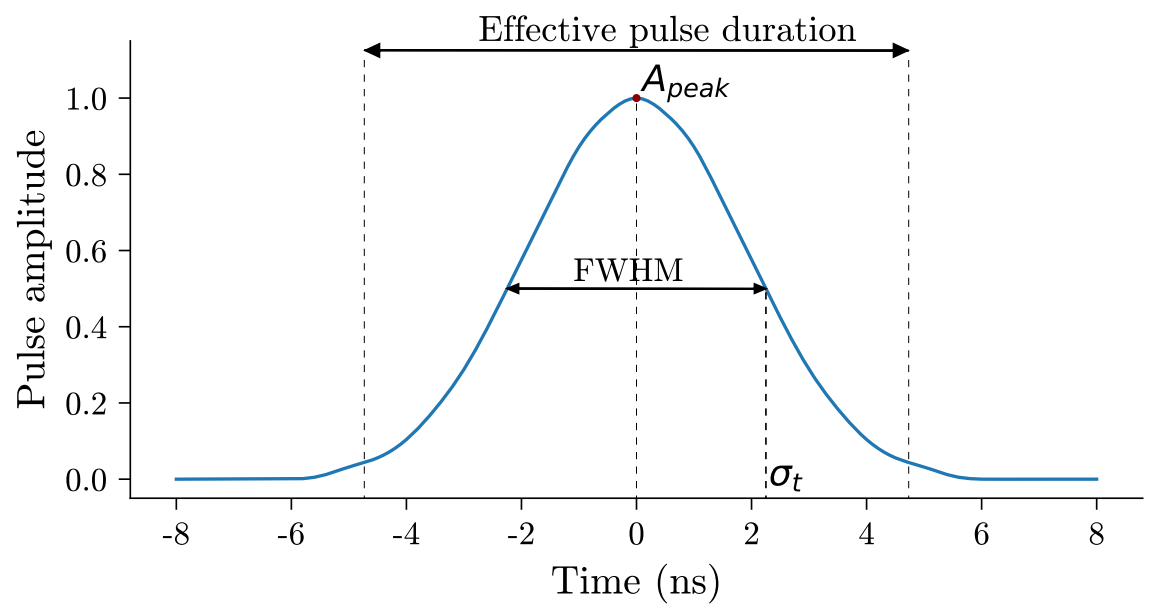

Figure 3. A temporal profile of a transmitted laser pulse generated by DART with a $\sigma_{t}$ value of $2.25 \mathrm{~ns}$, a pulse duration at full-width half-maximum of $4.5 \mathrm{~ns}$ and an effective pulse duration of $9.5 \mathrm{~ns}$. The Gaussian shape and duration of the transmitted pulse is consistent with prior simulation studies using the RIEGL LMS-Q680i sensor [204,207].

The distribution of laser energy in each pulse footprint was simulated using a two-dimensional super-Gaussian distribution:

$$
P_{1}(\beta)=\hat{P}_{1, \beta} \cdot \exp \left(-\left(\frac{\beta^{2}}{2 \sigma_{\beta}^{2}}\right)\right)
$$

where $\hat{P}_{1, \beta}$ denotes the ratio of pulse energy to the central maximum, $\beta$ is the angular offset from the pulse direction and $\sigma_{\beta}$ is the two-dimensional standard deviation of laser energy [203]. The dispersal of laser energy in each pulse footprint was varied by adjusting $\sigma_{\beta}$ between 0.2 and 0.5 (Figure 4). The use of a Gaussian pulse footprint was consistent with the work of Armston [207]; however we could not validate this assumption due to a lack of published research documenting the laser energy profile employed by the RIEGL LMS-Q680i sensor. 

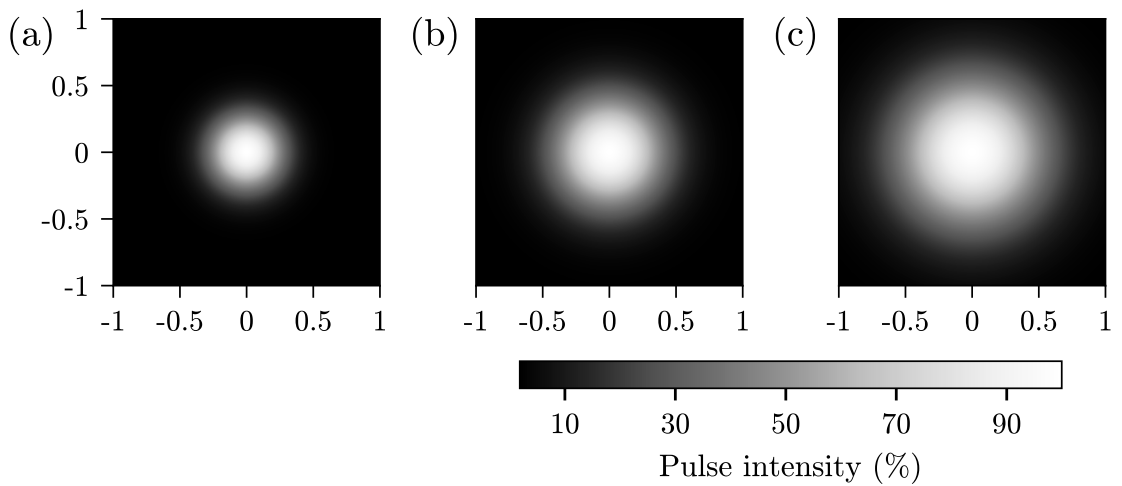

(d)

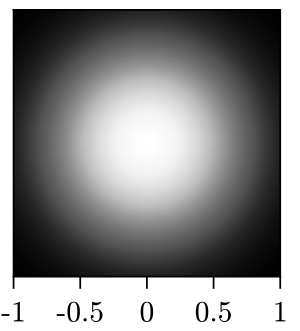

Figure 4. Gaussian laser energy distributions with a standard deviation $\left(\sigma_{\beta}\right)$ of $0.2,0.3,0.4$ and 0.5 ( $\mathbf{a}, \mathbf{b}, \mathbf{c}$ and $\mathbf{d}$ respectively). A $\sigma_{\beta}$ value of 0.99 would disperse laser energy uniformly across the pulse footprint [203].

\subsection{Discrete-Return Metrics}

The simulated waveforms from DART were stored in the Sorted Pulse Data (SPD) format [177] and Gaussian waveform decomposition was undertaken in SPDLib [188] with an algorithm designed to replicate the results of RiAnalyze [208]. Normalized discrete-return heights were then calculated by comparing return elevations to the digital terrain surface imported into each DART simulation. Discrete returns were classified as: (i) ground returns if they were within $\pm 1 \mathrm{~m}$ of the terrain, or (ii) vegetation if returns were $\geq 2 \mathrm{~m}$ above ground. We also tested several automated ground detection methods in SPDLib (e.g., progressive morphology filter [189], multi-scale curvature algorithm [190], parameter-free filtering algorithm [209]); however a simple threshold proved to be superior to automated methods since we could exploit prior knowledge of the ground surface imported into each DART simulation.

Area-based metrics (Table 3) were calculated at the individual plot scale $\left(400 \mathrm{~m}^{2}\right)$ using custom Python scripts that were multi-threaded with GNU Parallel [210]. Discrete-return metrics included height percentiles often used for the indirect retrieval of forest inventory parameters $[52,53]$. Canopy cover and gap fraction indices quantified the degree of canopy openness [16], while the relative abundance of single, multiple and ground returns provided a measure of laser penetration rates [211]. Gap fraction was calculated using all return classes (i.e., first, intermediate and last echoes) as this formulation was similar to the All-echo cover index that had proven to be successful in detecting small gaps in closed-canopy forests [212,213]. Canopy cover was calculated using a grid-based binary classification method [13] as the percentage of pixels (at 0.5-meter resolution) containing vegetation returns above $2 \mathrm{~m}$. Thus, canopy cover as defined here represents the proportion of the forest floor occluded by the vertical projection of tree crowns (vertical canopy cover) rather than the proportion of sky obscured by vegetation (angular canopy closure) [214,215]. This method was chosen as it provides an unbiased estimate of vertical canopy cover while being sensitive to variations in discrete-return density and laser scanning angle [13].

Voxel-based canopy volume metrics [216] were also calculated to investigate the vertical and horizontal variability of discrete returns generated by the DART simulations. Voxels $\left(1 \mathrm{~m}^{3}\right)$ above the 65th height percentile $\left(\mathrm{h}_{65}\right)$ and containing laser returns were classified as Euphotic to represent the overstory where the bulk of incoming radiation was intercepted. Conversely, voxels below $\mathrm{h}_{65}$ and containing laser returns were defined as Oligophotic to represent the partially obscured understory. The Euphotic and Oligophotic voxels together represented the filled canopy volume, whereas voxels lacking laser returns were classified as Open Gaps or Closed Gaps depending on their relative positions above or below the forest canopy $[217,218]$. The raw counts of voxel class membership were converted into normalized percentages to facilitate comparisons across all DART simulations. 
Table 3. Discrete-return metrics calculated for each DART simulation.

\begin{tabular}{|c|c|c|}
\hline Name & Definition & References \\
\hline Canopy Cover $(\%)$ & $\begin{array}{l}\text { Percentage of grid cells at } 0.5 \mathrm{~m} \text { resolution } \\
\text { containing vegetation returns above } 2 \mathrm{~m} \text {. }\end{array}$ & [13] \\
\hline Gap Fraction ( $\rho$ Gap) & $1-\left(\right.$ Returns $_{V e g}>2 m /$ Returns $\left._{A l l}\right)$ & {$[212,213]$} \\
\hline Ground return $(\%)$ & Percentage of discrete returns classified as ground. & \\
\hline $\mathrm{h}_{25}-\mathrm{h}_{\max }$ & Height percentiles of vegetation returns above $2 \mathrm{~m}$. & [48] \\
\hline $\mathrm{h}_{\text {mean }}$ & Mean height of vegetation returns above $2 \mathrm{~m}$. & \\
\hline Multiple return (\%) & Percentage of laser pulses with multiple returns. & \\
\hline Return density & Mean number of discrete returns per $\mathrm{m}^{2}$. & \\
\hline Single return $(\%)$ & Percentage of laser pulses with single returns. & \\
\hline Canopy volume metrics & $\begin{array}{l}\text { Percentage of } 1 \mathrm{~m}^{3} \text { voxels classified as Closed gap, } \\
\text { Open gap, Oligophotic or Euphotic. }\end{array}$ & {$[216-218]$} \\
\hline
\end{tabular}

\subsection{Sensitivity Analysis}

Following guidelines set out by Saltelli and Annoni [111] and Saltelli et al. [113], our experiment was divided into two stages:

(i) an uncertainty analysis was undertaken to determine the accuracy and precision of discrete-return measurements generated by the DART model,

(ii) a sensitivity analysis was conducted to identify the acquisition parameters that had caused greatest variability in the simulated discrete-return metrics.

To achieve the first objective, 500 DART simulations were performed over each of the reconstructed forest plots (50,000 simulations in total) using a sequence of acquisition parameters generated through a maximin Latin hypercube sampling of the parameter bounds identified in Table 2. This sampling approach ensured that: (i) the simulation parameters were sampled uniformly across the parameter feature-space, and (ii) the same acquisition parameters were repeatedly tested over each of the 100 forest inventory plots. We evaluated the precision of the simulated ALS metrics using a reliability ratio:

$$
\text { Reliability ratio }=\frac{\hat{\sigma}_{u}^{2}}{\hat{\sigma}_{u}^{2}+\hat{\sigma}_{w}^{2}}
$$

where $\hat{\sigma}_{u}^{2}$ represents the between-plot variance and $\hat{\sigma}_{w}^{2}$ denotes the within-plot variance of each ALS metric [82,219]. A reliability ratio close to 1 indicated that DART simulations had produced precise ALS metrics, whereas values closer to zero demonstrated that changes to the acquisition parameters had produced ALS metrics with a high degree of within-plot variance, thus making these ALS metrics unreliable predictors for the derivation of forest inventory parameters. For comparison purposes, we also calculated the Fisher ratio:

$$
\text { Fisher ratio }=\frac{\hat{\sigma}_{u}^{2}}{\hat{\sigma}_{w}^{2}}
$$

to examine the ratio of between-plot to within-plot variance for each ALS metric [220]. Two-sample Kolmogorov-Smirnov and Anderson-Darling tests [221-223] were then performed to investigate whether the simulated height percentiles were statistically similar those recorded within the reference ALS survey.

For the second objective, a sequence of 20,000 acquisition parameters were generated to perform a variance-based global sensitivity analysis in SALib [224] using the Sobol method [225-227]. 
The acquisition parameters were tested sequentially over one of the simulated forest plots (illustrated in Figure 2), and the unconditional variance of each ALS metric $V(y)$ was decomposed following:

$$
V(y)=\sum_{i=1}^{n} V_{i}+\sum_{i \leq j \leq n}^{n} V_{i j}+\ldots+\sum_{i \leq n}^{n} V_{1 \ldots n}
$$

where $V_{i}$ denotes the first-order contribution of the $i$ th model parameter, $V_{i j}$ represents the pairwise interaction of the $i$ th and $j$ th parameters and $n$ is the number of acquisition parameters. First, second, and total order of sensitivity indices were then calculated:

$$
\begin{gathered}
S_{i}=\frac{V_{i}}{V(y)} \\
S_{i j}=\frac{V_{i j}}{V(y)} \\
S_{T_{i}}=1-\frac{V_{\sim i}}{V(y)}
\end{gathered}
$$

where $V_{\sim i}$ denotes the contribution from all simulation parameters excluding the $i$ th parameter. First-order sensitivity indices quantified the output variance directly attributable to parameter $i$ without considering parameter interactions. Conversely, total order sensitivity indices quantified the variance attributable to parameter $i$ when including interactions with other simulation parameters [228,229]. Additive simulation outputs lacking parameter interactions were expected to have identical $S_{i}$ and $S_{T_{i}}$ indices with the sum of total order indices $\left(\sum S_{T_{i}}\right)$ converging at unity. In contrast, strong interactions between the simulation parameters were expected to produce divergent sensitivity indices and $\sum S_{T_{i}}$ values exceeding unity [111].

\section{Results}

\subsection{Uncertainty Analysis}

100 fixed-area $\left(400 \mathrm{~m}^{2}\right)$ plots were reconstructed with biometrics similar to those recorded in the forest inventory campaign (Figure 5). Tree density was reproduced with a root-mean-square error (RMSE) of 67 trees ha ${ }^{-1}(5.6 \%)$, while basal area, mean DBH and mean tree height were replicated with errors of $1.7 \mathrm{~m}^{2} \mathrm{ha}^{-1}(5.4 \%), 1.4 \mathrm{~cm}(7.3 \%)$ and $0.67 \mathrm{~m}(4.7 \%)$ respectively. These results demonstrated a good correspondence between the field measurements and the biometrics of simulated plots, consequently the DART simulations were representative of stands measured during the forest inventory.

The DART simulations produced discrete-return height percentiles with limited within-plot variance as demonstrated by high Fisher ratios and reliability ratios $>0.97$ (Table 4). Strong reliability ratios $(>0.99)$ were produced for all height percentiles above $h_{50}$, demonstrating that discrete-return height distributions in the upper forest canopy were highly stable and insensitive to variations in sensor configuration, ground topography or DART model parameterization. Height percentiles in the lower forest canopy were marginally less precise, with reliability ratios of 0.99 and 0.97 for $h_{\text {mean }}$ and $h_{25}$ respectively.

Weak reliability ratios were recorded for discrete-return density (0.108), canopy cover (0.675), the proportion of multiple canopy returns (0.559) and the proportion of Euphotic (0.588) and Oligophotic (0.367) voxels. The high proportion of within-plot variance for these ALS metrics demonstrated that changes to the acquisition parameters had significantly influenced: (i) the density and horizontal distribution of discrete returns, and (i) the extent of laser pulse penetration through the simulated forest canopies. Despite this, gap fraction and the proportion of voxels classified as open and closed gaps produced comparatively strong reliability ratios of $0.932,0.896$ and 0.913 
respectively, indicating that gap fraction indices were relatively stable despite perturbations to the acquisition parameters.

Table 4. Reliability metrics for DART simulations repeated over 100 forest plots.

\begin{tabular}{|c|c|c|c|c|}
\hline ALS Metric & Reliability Ratio & Pooled Mean & Pooled SD & Fisher Ratio \\
\hline \multicolumn{5}{|c|}{ Return density and laser penetration metrics } \\
\hline Canopy Cover (\%) & 0.675 & 81.26 & 6.65 & 2.08 \\
\hline Gap Fraction ( $\rho$ Gap) & 0.932 & 0.35 & 0.03 & 13.64 \\
\hline Ground return $(\%)$ & 0.928 & 34.59 & 3.12 & 12.84 \\
\hline Multiple return $(\%)$ & 0.559 & 55.40 & 4.03 & 1.27 \\
\hline Return Density & 0.108 & 18.89 & 5.94 & 0.12 \\
\hline \multicolumn{5}{|c|}{ Height metrics } \\
\hline $\mathrm{h}_{\text {mean }}$ & 0.990 & 11.34 & 0.34 & 100.59 \\
\hline $\mathrm{h}_{25}$ & 0.971 & 9.35 & 0.55 & 33.15 \\
\hline $\mathrm{h}_{50}$ & 0.988 & 11.44 & 0.40 & 81.61 \\
\hline $\mathrm{h}_{60}$ & 0.991 & 12.19 & 0.35 & 114.93 \\
\hline $\mathrm{h}_{70}$ & 0.995 & 12.96 & 0.28 & 194.48 \\
\hline $\mathrm{h}_{75}$ & 0.996 & 13.35 & 0.25 & 254.70 \\
\hline $\mathrm{h}_{80}$ & 0.997 & 13.77 & 0.22 & 340.44 \\
\hline $\mathrm{h}_{90}$ & 0.998 & 14.79 & 0.18 & 521.11 \\
\hline $\mathrm{h}_{95}$ & 0.998 & 15.54 & 0.18 & 601.72 \\
\hline $\mathrm{h}_{99}$ & 0.998 & 16.74 & 0.22 & 413.43 \\
\hline $\mathrm{h}_{\max }$ & 0.994 & 18.05 & 0.35 & 181.95 \\
\hline \multicolumn{5}{|c|}{ Canopy volume metrics } \\
\hline Closed Gap (\%) & 0.913 & 32.67 & 2.62 & 10.44 \\
\hline Euphotic (\%) & 0.588 & 14.19 & 2.30 & 1.43 \\
\hline Oligophotic (\%) & 0.367 & 18.88 & 3.13 & 0.58 \\
\hline Open Gap (\%) & 0.896 & 34.26 & 3.52 & 8.58 \\
\hline
\end{tabular}

Note: $\mathrm{SD}=$ standard deviation.
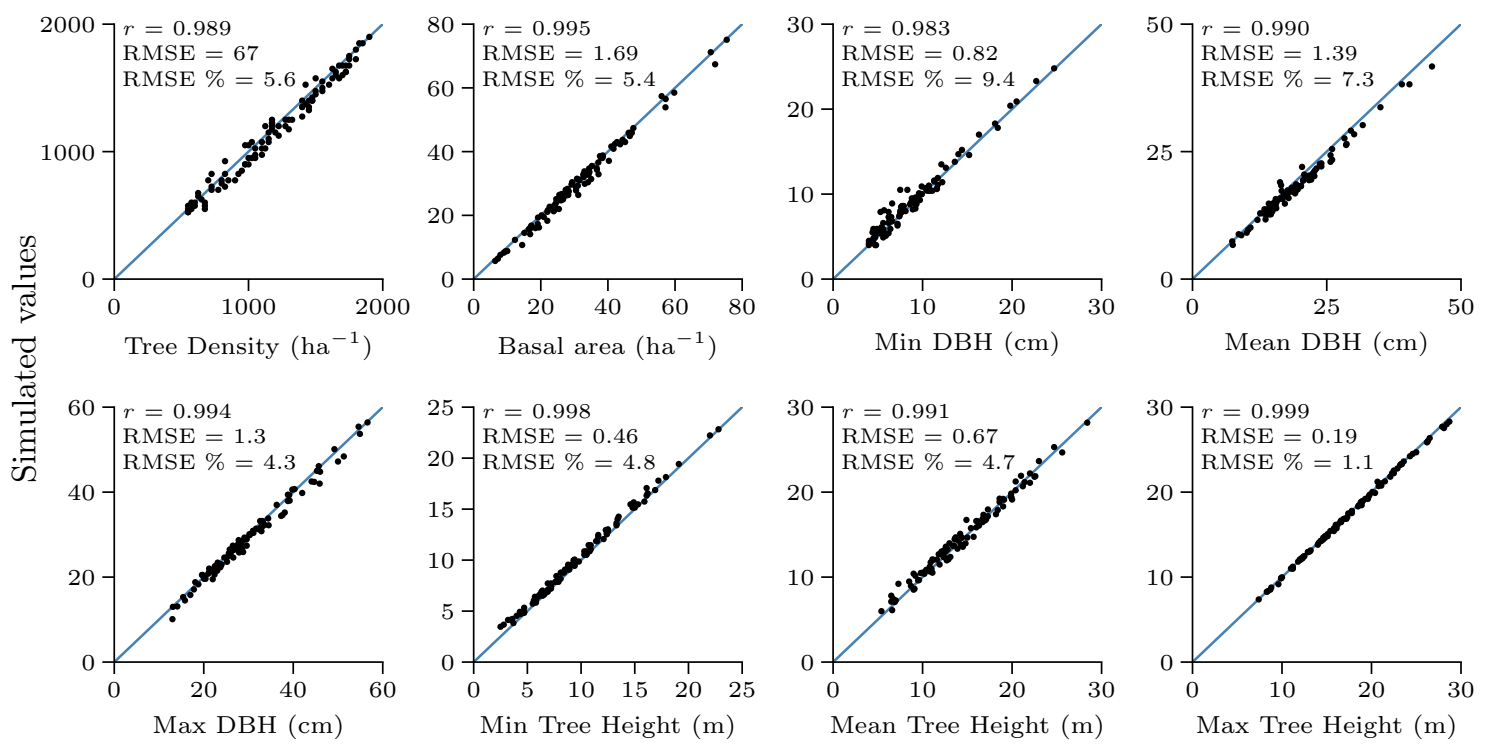

Observed values

Figure 5. Scatter diagrams comparing modeled versus observed biometrics across 100 forest inventory plots simulated with the DART model. The blue diagonal line represents a perfect (i.e., one-to-one) correspondence between the simulated and observed plot metrics. $r=$ Pearson correlation coefficient. 
The Anderson-Darling and Kolmogorov-Smirnov tests demonstrated that the simulated discrete-return height percentiles were consistent (at the $99 \%$ confidence interval) with those recorded in the reference survey (Table 5). Encouragingly, most DART simulations produced height errors of $\pm 1.5 \mathrm{~m}$ (Figure $6 \mathrm{a})$, with a mean absolute error of $0.58 \pm 0.46 \mathrm{~m}(3.3 \pm 2.6 \%)$ for $h_{\max }$. The mean error for $h_{\max }$ across all simulations was $-0.31 \mathrm{~m}$, indicating that the top of canopy height was often underestimated and therefore negatively biased. However, discrete-return height percentiles within the upper forest canopy $\left(\mathrm{h}_{60}-\mathrm{h}_{99}\right)$ were notably more accurate and precise than those simulated in the lower forest canopy as median height and $\mathrm{h}_{25}$ were underestimated by $-0.8 \mathrm{~m}(6.3 \%)$ and $-1.0 \mathrm{~m}$ $(9.7 \%)$ respectively.

Table 5. Anderson-Darling and Kolmogorov-Smirnov two-sample tests of homogeneity for discretereturn height percentiles obtained from DART simulations and from the reference ALS survey. $p$-values $\geq 0.05$ denote homogeneous distributions at the $95 \%$ confidence interval.

\begin{tabular}{ccccc}
\hline \multirow{2}{*}{ Height Percentile } & \multicolumn{2}{c}{ Anderson-Darling } & \multicolumn{2}{c}{ Kolmogorov-Smirnov } \\
& $\boldsymbol{T}_{\boldsymbol{m} \boldsymbol{n}}$ & $\boldsymbol{p}$-Value & $\boldsymbol{D}_{\boldsymbol{m} \boldsymbol{n}}$ & $\boldsymbol{p}$-Value \\
\hline $\mathrm{h}_{25}$ & 0.32 & 0.25 & 0.15 & 0.19 \\
$\mathrm{~h}_{50}$ & -0.29 & 0.47 & 0.14 & 0.26 \\
$\mathrm{~h}_{60}$ & -0.54 & 0.62 & 0.10 & 0.68 \\
$\mathrm{~h}_{70}$ & -0.83 & 0.84 & 0.09 & 0.79 \\
$\mathrm{~h}_{75}$ & -0.89 & 0.90 & 0.09 & 0.79 \\
$\mathrm{~h}_{80}$ & -0.87 & 0.87 & 0.10 & 0.68 \\
$\mathrm{~h}_{90}$ & -0.94 & 0.95 & 0.10 & 0.68 \\
$\mathrm{~h}_{95}$ & -0.99 & 1.00 & 0.10 & 0.68 \\
$\mathrm{~h}_{99}$ & -0.88 & 0.89 & 0.11 & 0.55 \\
$\mathrm{~h}_{\text {max }}$ & -0.74 & 0.76 & 0.14 & 0.26
\end{tabular}

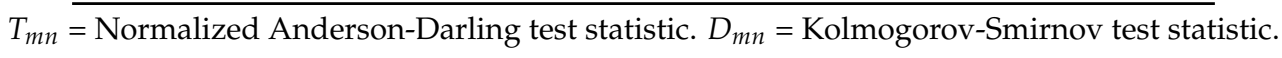

(a)

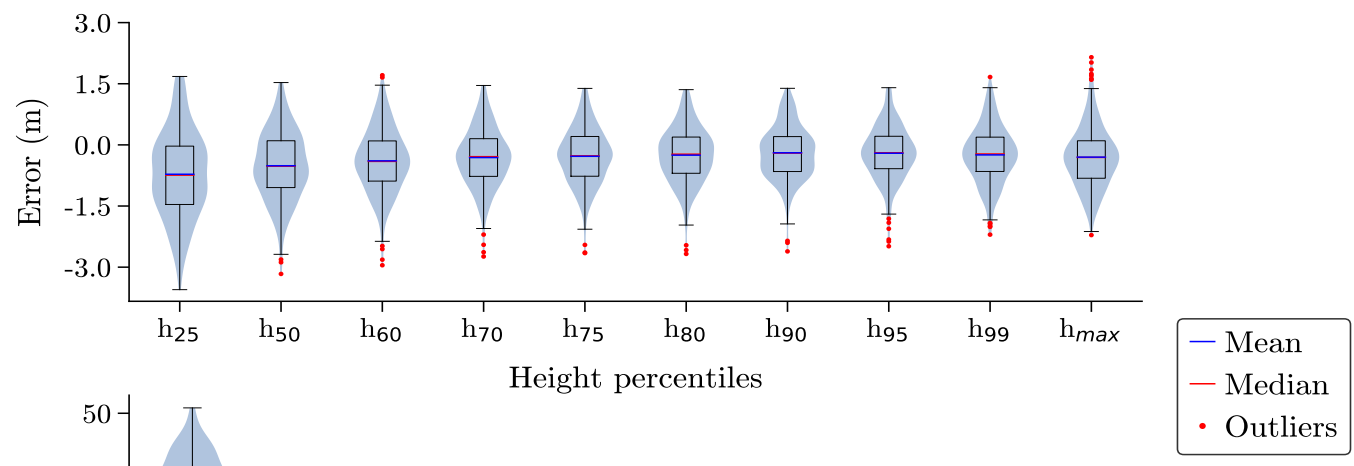

(b)

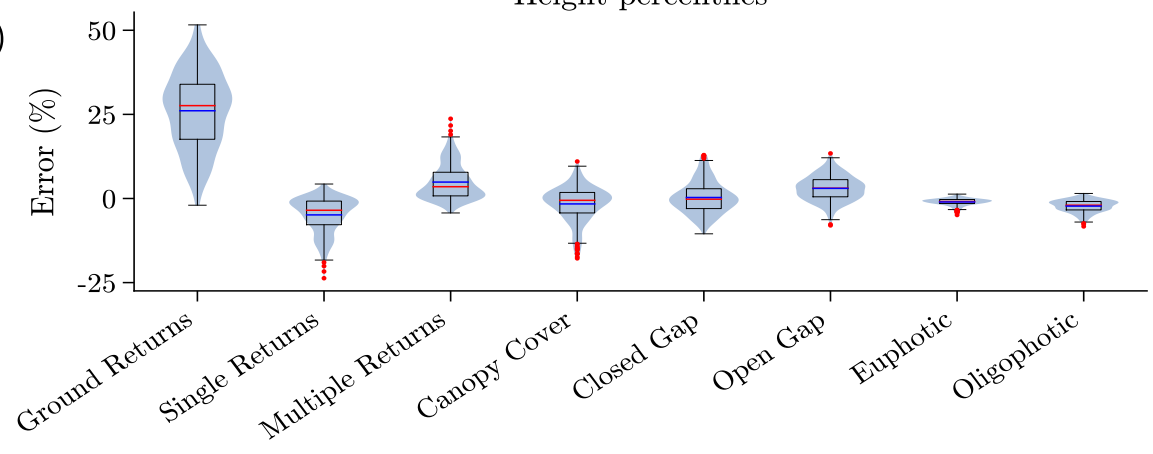

Canopy cover metrics

Figure 6. Violin plots illustrating errors in the simulated height percentiles (a) and canopy cover metrics (b) when compared against observations from the reference ALS survey.

The canopy cover and laser penetration metrics generated by DART proved to be highly accurate when compared against the reference survey (Figure 6b). Canopy cover was simulated 
with a mean absolute percentage error (MAPE) of 3.92\%, while the voxel-based canopy volume metrics were simulated with mean errors below 3.85\%. However, our DART simulations consistently overestimated the proportion of multiple returns $(\mathrm{MAPE}=5.1 \%$ ), while the number of ground returns was overestimated by $26.1 \%$.

\subsection{Sensitivity Analysis}

The sensitivity analysis revealed that laser scanning angle, pulse repetition frequency and sensor altitude had exerted a significant influence across all of the discrete-return metrics (Figure 7). These three acquisition parameters accounted for $75-83 \%$ of the total recorded variance in the discrete-return height percentiles (Figure 7i-1). Scan angle exerted an important influence on discrete return density, canopy cover and discrete return heights $\left(S_{T_{i}}=0.40-0.46\right)$. However, pulse frequency also significantly influenced discrete return density and height distributions throughout the forest canopy $\left(S_{T_{i}}=0.33-0.36\right)$. The voxel-based canopy volume metrics were strongly influenced by scan angle $\left(S_{T_{i}}=0.36-0.44\right)$ and $\operatorname{PRF}\left(S_{T_{i}}=0.30-0.35\right)$, highlighting the importance of these two simulation parameters in governing both the horizontal and vertical distribution of the discrete returns.

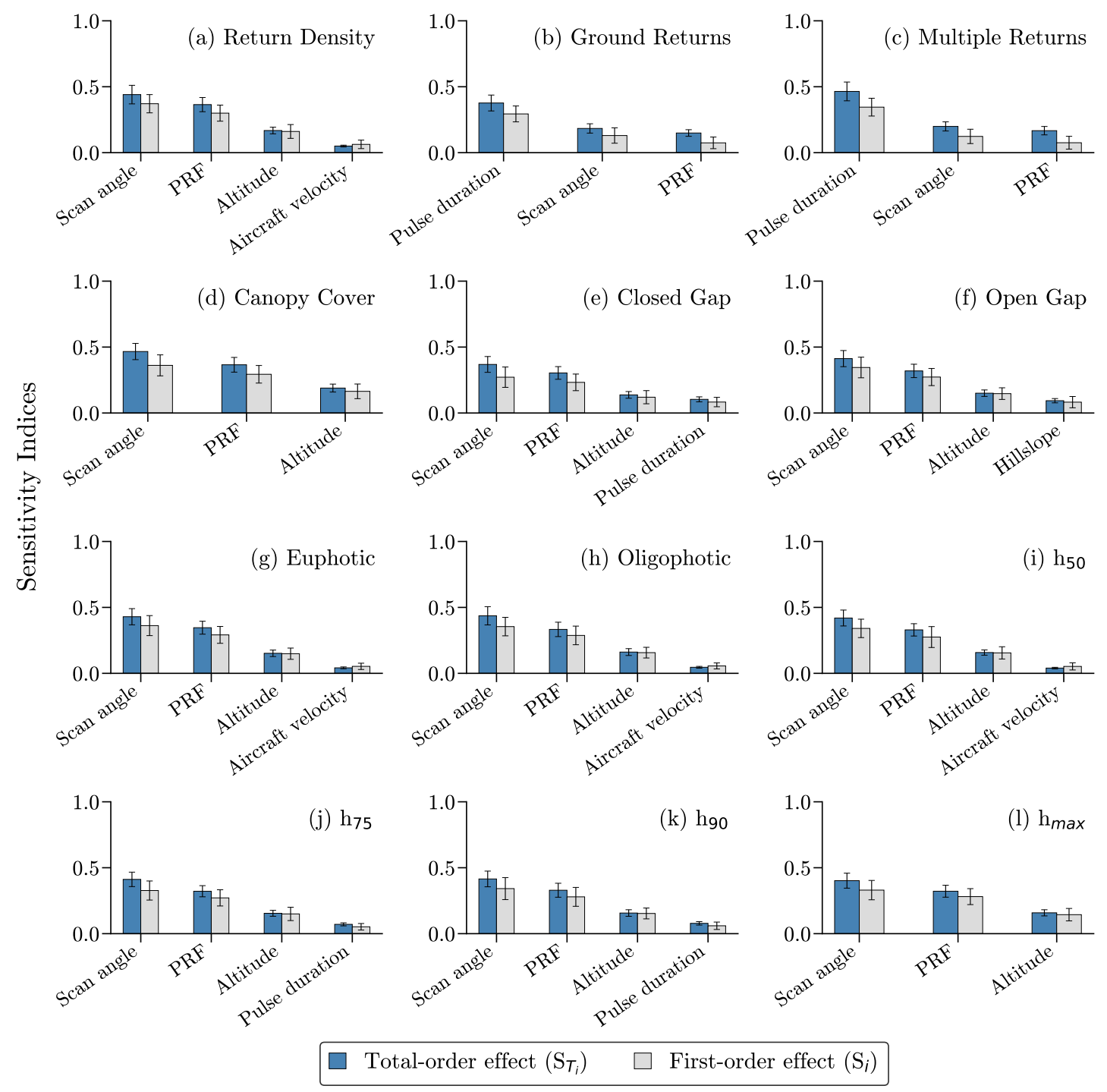

Figure 7. First and total order sensitivity indices as determined by the variance-based sensitivity analysis. The most sensitive parameters are ranked according to their first-order sensitivity indices. Simulation parameters with negligible first and total order effects are not illustrated for clarity. 
Interestingly, the DART model parameters (propagation threshold, scattering directions, scattering order, sub-center photons and voxel resolution) exerted a negligible influence on the simulated ALS metrics. First and total order sensitivity indices for these simulation parameters were consistently below 0.05 and statistically indistinguishable from zero due to large standard errors. These results demonstrated that DART parameters could be fixed at constant values to reduce the parameterization of future simulations.

We found little evidence of strong interactions between the simulation parameters, as shown by: (i) the homogeneity of total and first-order sensitivity indices (Figure 7), and (ii) the lack of strong second-order sensitivity indices. For instance, sensor altitude, PRF and sensor altitude exerted an important influence on $\mathrm{h}_{\max }$ (Figure 7l); however we did not observe strong second-order interactions between scan angle and $\operatorname{PRF}\left(S_{i j}=0.072\right)$, scan angle and sensor altitude $\left(S_{i j}=0.05\right)$ or between PRF and sensor altitude $\left(S_{i j}=0.009\right)$. The lack of second-order interactions indicated that the discrete-return metrics were the result of additive or multiplicative processes that could be approximated through univariate functions. However, response curves (Figure 8) revealed a variety of non-linear and non-monotonic relationships, indicating that the discrete-return metrics could not be readily approximated through a linear combination of the simulation parameters.
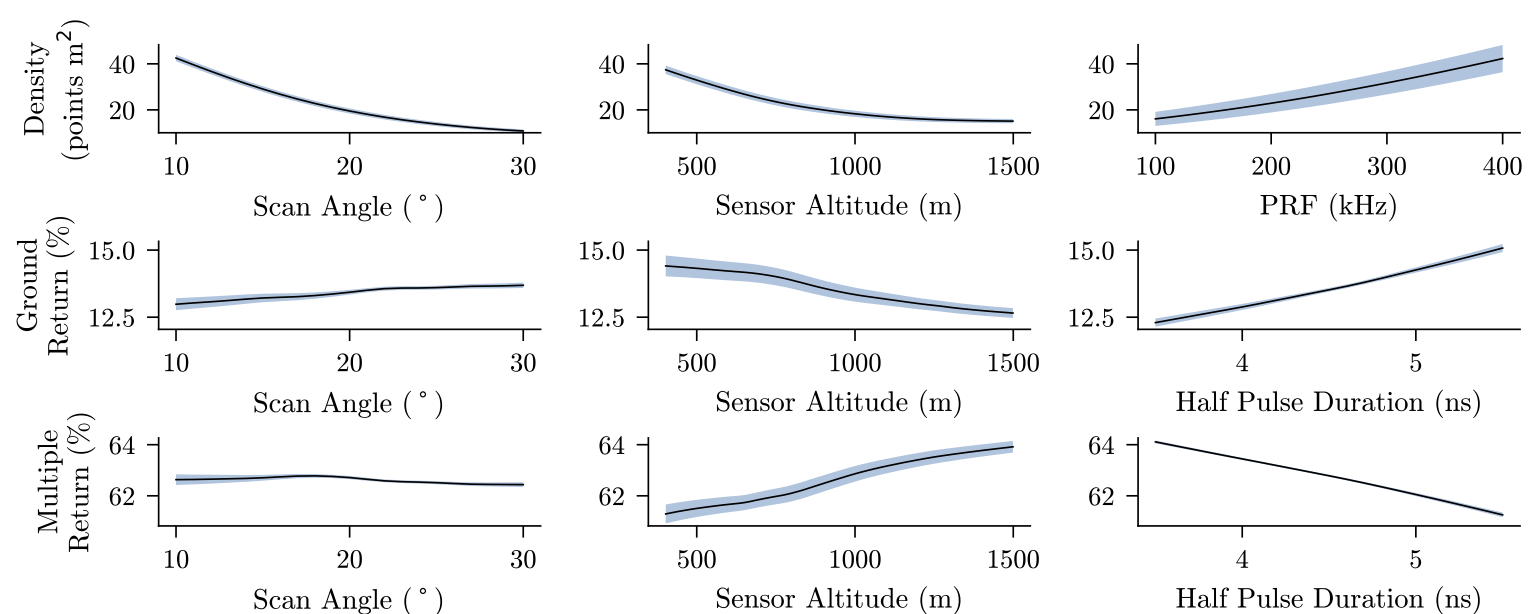

Half Pulse Duration (ns)

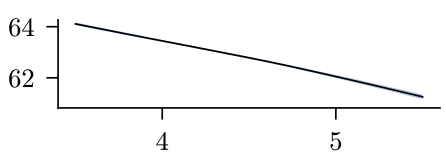

Half Pulse Duration (ns)
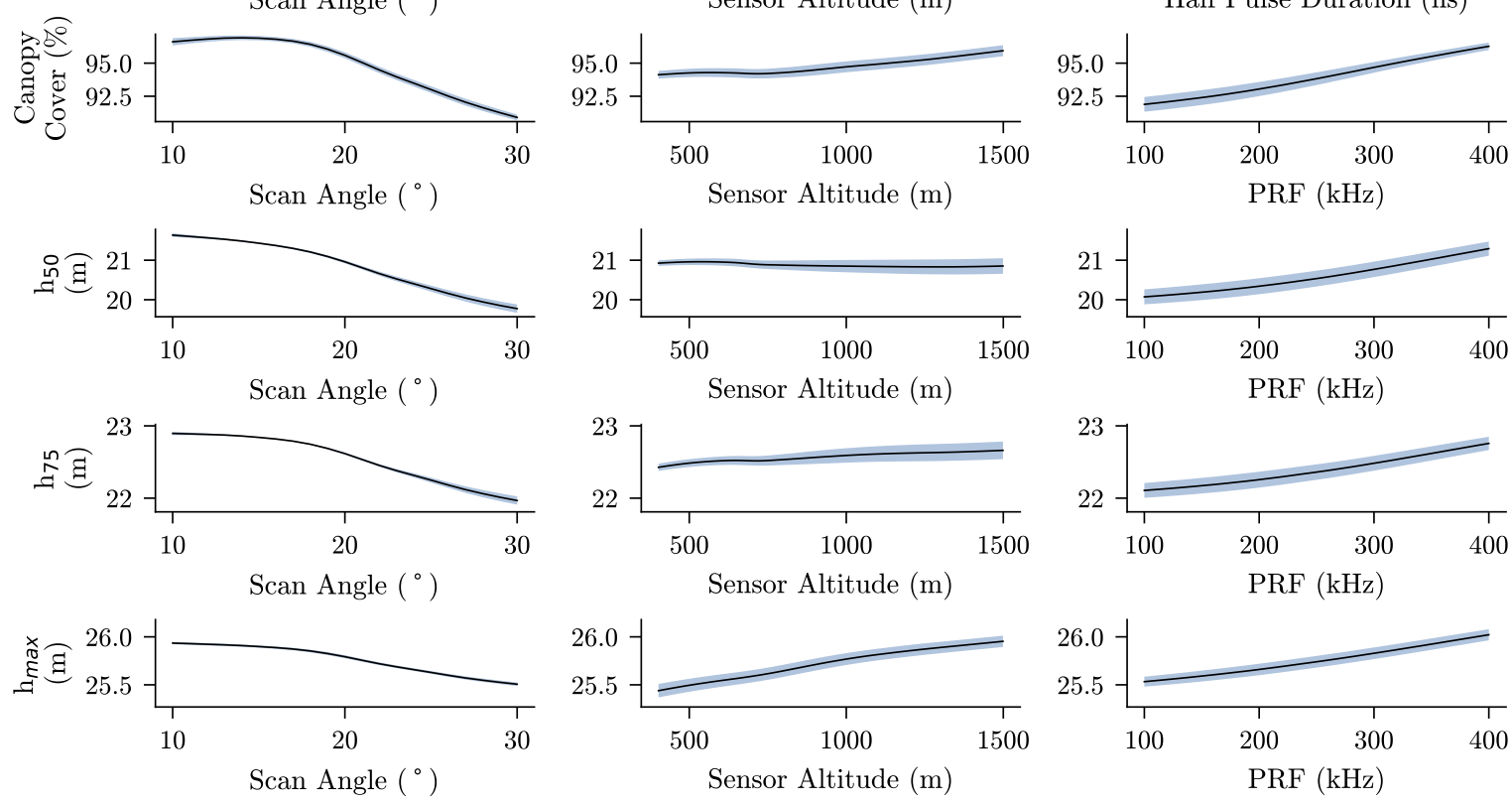

Mean Response $\square 95 \%$ Confidence Interval

Figure 8. Response curves illustrating the influence of individual acquisition parameters on discrete-return metrics obtained from the DART model. 
Wider scan angles were associated with a reduction in the discrete-return height distributions (Figure 8) as a larger proportion of pulses interacted with crown edges rather than tree apices. This downwards shift in the discrete-return heights was most pronounced at wider scanning angles, with height percentiles declining by more than $0.5 \mathrm{~m}$ as the maximum scanning angle increased from $20^{\circ}$ to $30^{\circ}$. We observed a similar trend for PRF, with lower pulse frequencies associated with a monotonic reduction in the ALS height percentiles as fewer returns were recorded at treetops. In contrast, rising sensor altitudes were associated with an upward shift in the discrete-return height distributions, with $h_{\max }$ rising by $0.5 \mathrm{~m}$ as the platform altitude increased from 400 to $1500 \mathrm{~m}$. For the ALS density and canopy cover metrics, we recorded a decline in the number of discrete returns as PRF was reduced and scan angle and sensor altitude increased. Interestingly, canopy cover decreased by $5 \%$ as the scan angle increased from $15^{\circ}$ to $30^{\circ}$. This marked decline in canopy cover at wider scan angles was an unexpected result caused primarily by the reduced discrete-return density at wider scan angles.

As noted in Section 4.1, the largest errors encountered in our DART simulations were associated with the proportion of ground and multiple canopy returns. Our sensitivity analysis revealed that pulse duration, scan angle and pulse repetition frequency were the main sources of variance for these two metrics (Figure $7 \mathrm{~b}, \mathrm{c}$ ). In both instances, the duration of transmitted pulses proved to be the dominant simulation parameter, with longer pulses triggering a monotonic increase in the number of ground returns and a decline in the proportion of multiple canopy returns (Figure 8). Further experiments revealed that longer pulse durations had caused a decline in the proportion of multiple returns due to the integration of backscatter signals from canopy and ground structures (Figure 9). These results demonstrated that Gaussian waveform decomposition was unable to resolve echoes from near-ground structures as half-pulse duration increased beyond $5 \mathrm{~ns}$.

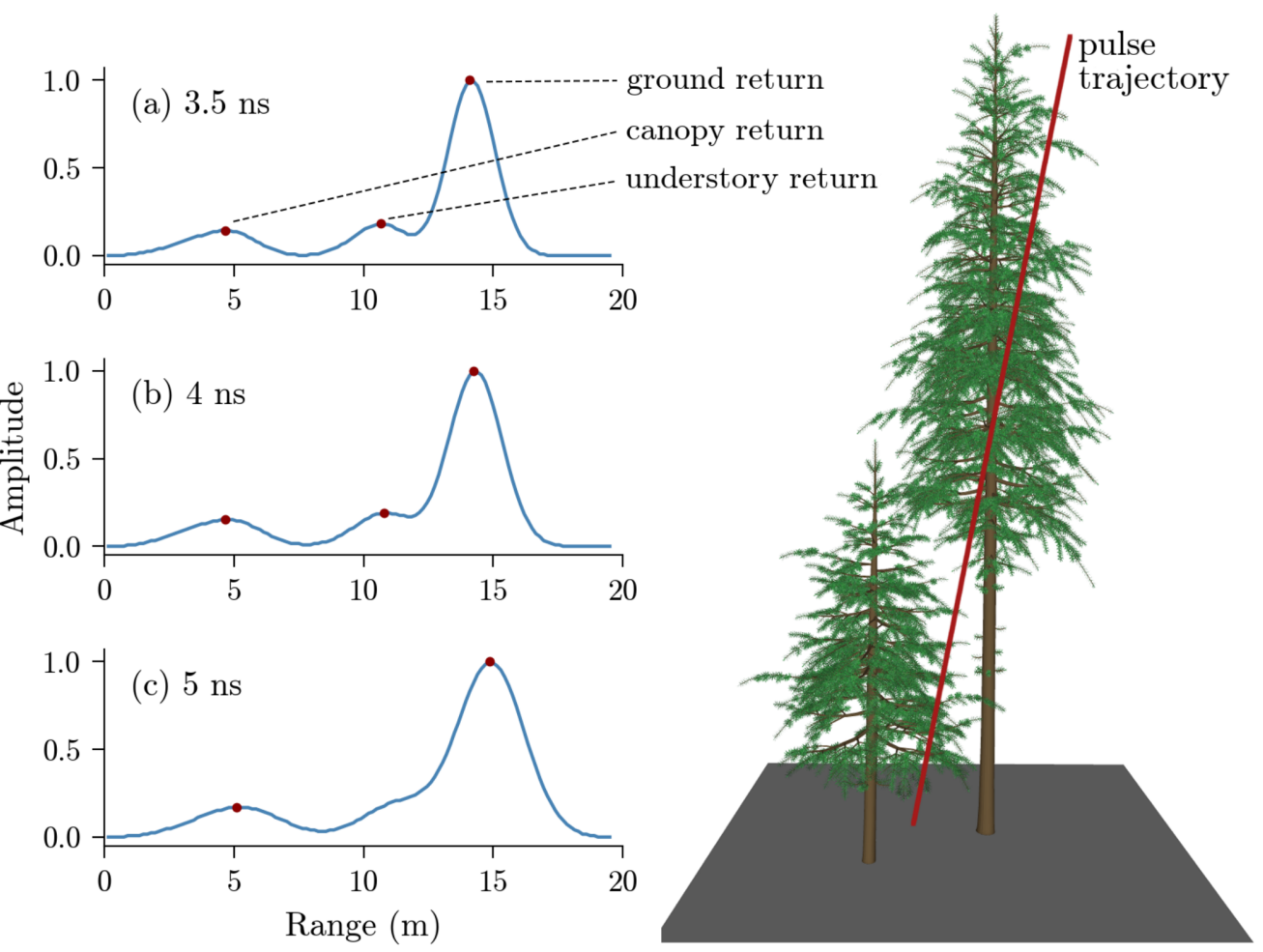

Figure 9. Received waveforms with transmitted pulse durations of 3.5, 4 and $5 \mathrm{~ns}$ at full-width half-maximum. Following Gaussian decomposition, the 5 ns pulse produced only two discrete returns due to the superposition of backscatter signals from the understory and forest floor. 


\section{Discussion}

In this study, a variance-based global sensitivity analysis was undertaken to: (i) investigate how accurately the DART model was able to reproduce ALS measurements acquired over commercial forests, and (ii) examine the impact of survey parameters on the precision of discrete-return metrics commonly used for the derivation of forest inventory measurements. While previous simulation studies had examined the influence of survey characteristics using local sensitivity analyses and/or abstract forest canopies, we attempted to undertake a more rigorous sensitivity analysis of the DART model using: (i) three-dimensional synthetic trees with explicitly defined crown geometries and reflectance properties, and (ii) a variance-based global sensitivity analysis that accounted for non-linear interactions between the ALS survey parameters.

\subsection{Simulation Accuracy}

The DART simulations successfully replicated discrete-return ALS measurements collected with the RIEGL LMS-Q680i sensor over commercial forests in the Republic of Ireland. Despite considerable modifications to the acquisition parameters, DART produced discrete-return height distributions that were accurate and precise across 100 forest inventory plots, with a mean absolute error of $0.58 \pm 0.46 \mathrm{~m}$ $(3.3 \pm 2.6 \%)$ for maximum canopy height. Canopy cover and canopy volume metrics were replicated with mean absolute percentage errors below $4 \%$, demonstrating the horizontal and vertical accuracy of discrete-return distributions produced by the DART model.

The canopy height errors generated by our simulations were consistent with those reported by Suárez et al. [230] and Donoghue and Watt [231] for plantation forests in Scotland and Northern England. Hence, our simulations produced canopy height errors that were comparable in magnitude to direct comparisons between ALS and ground-based canopy height measurements in British conifer plantations. However, we acknowledge that our experiments did not take into consideration common biophysical features of plantation forests such as the presence of forked or wolf trees, nor did we account for height discrepancies induced by tree lean on steep terrain [232,233]. We also acknowledge that the forests used in our simulations were simplified representations of the Slieve Aughty plantations since they were parameterized primarily for Sitka spruce monocultures and did not account for nutrient deficient or waterlogged soils [234], broadleaf encroachment [235], silvicultural treatments (thinning and pruning regimes) and stochastic events such as windblow [236] which regularly impact forest structure and alter the reflectance signal recorded by ALS instruments.

Our simulations consistently overestimated the proportion of multiple canopy returns $(\mathrm{MAPE}=5.1 \%$, while the proportion of ground returns was overestimated by $26.1 \%$. These large inaccuracies revealed that the simulated forest canopies were too porous, causing an insufficient number of pulses to be wholly reflected by the forest canopy in order to occlude the ground surface. The lack of ground vegetation in our simulations may have contributed towards more penetrable forest canopies; however it is unlikely that this was a dominant factor given the paucity of understory vegetation in conifer plantations throughout Britain and Ireland. It is also feasible that the elevated number of ground returns recorded in our simulations was symptomatic of ground misclassification during the processing of the reference ALS dataset. However, our experiments suggest that the elevated number of ground and multiple returns were primarily caused by structural inaccuracies in the simulated trees due to the inadequate representation of foliage. This finding is supported by previous studies demonstrating the importance of needle morphology, density and orientation in governing multiple scattering in coniferous forests [237,238]. In particular, Rochdi et al. [239] recorded high levels of multiple scattering when performing radiative transfer experiments with shoots comprised of realistic needles, whereas shoots consisting of abstract needles produced little multiple scattering due to shoot impermeability. Our study therefore highlights the complexities of: (i) generating synthetic trees that are biologically realistic, and (ii) parameterizing tree modeling software such as OnyxTree, Arbaro [240] or AMAPstudio [184] based on manual field measurements. In future investigations, it may be preferable to perform radiative transfer simulations using trees digitized directly from 
terrestrial laser scanning measurements [99,124,185,187] or digital photogrammetry [241] since these techniques can enable the importation of biologically realistic trees.

\subsection{Precision of ALS Metrics}

The DART simulations produced discrete-return height metrics that were consistent across 100 forest inventory plots, with little evidence of deleterious perturbations induced by varying acquisition parameters or ground topography. These findings supported the findings of previous investigations indicating that discrete-return heights are robust to moderate variation in survey conditions $[69,72,219]$ and may therefore provide reliable predictor variables for the indirect retrieval of forest inventory measurements across different ALS surveys [70,242,243]. Conversely, discrete-return density, canopy cover and the proportion of multiple canopy returns were sensitive to variations in sensor altitude, laser scanning angle, pulse repetition frequency and transmitted pulse duration, indicating that these survey characteristics play an important role in governing the stability of discrete-return metrics obtained from different ALS surveys. These latter findings indicate that canopy cover and density metrics are only directly comparable for discrete-return data collected under similar survey conditions and are less reliable predictor variables for the retrieval of forest biometrics. Furthermore, the proportion of multiple canopy returns acquired using different survey parameters was highly sensitive to variations in laser pulse duration and scanning angle, indicating that ALS metrics derived from intermediate and last returns are not consistent between surveys and should be avoided where possible. Our DART simulations therefore corroborate similar findings reported in controlled ALS surveys by Morsdorf et al. [63], Næsset [66], Jakubowski et al. [61], Keränen et al. [67] and Sumnall et al. [244].

\subsection{Impact of Acquisition Parameters}

The DART simulations demonstrated that lower pulse repetition frequencies and wider scanning angles can cause a downward shift in discrete-return heights as a greater proportion of returns are recorded at crown edges rather than treetops. Discrete-return height percentiles declined by $\sim 0.5 \mathrm{~m}$ as laser scanning angles increased from $20^{\circ}$ to $30^{\circ}$, indicating that wider scan angles $\left(>20^{\circ}\right)$ may be sub-optimal for forests where tree apices are conical with well-defined leaders. Our simulations also revealed that wider scan angles $\left(>20^{\circ}\right)$ may produce inaccurate canopy cover measurements due to a reduction in discrete-return density. These findings are supported by Holmgren et al. [106] who recorded a similar downward shift in the ALS height percentiles and perturbations to canopy cover measurements at wider scan angles. Holmgren et al. [106] found that these effects were most pronounced at the edges of the ALS swath. However, the magnitude of these effects was also dependent on stocking density and crown morphology, with dense stands of trees with elongated crowns experiencing a smaller downward shift in discrete-return height percentiles due to the occlusion of the lower forest canopy.

Our results contrasted with those of Chasmer et al. [74], Hopkinson [75] and Næsset [66] who reported an upward shift in canopy height distributions at lower pulse repetition frequencies. The authors attributed this trend to an increase in peak pulse power at lower pulse frequencies, causing an upwards shift in discrete-return heights as pulses did not penetrate far into the forest canopy before triggering a return signal. We found little evidence of these pulse interactions in our DART simulations, potentially reflecting inaccuracies in tree morphology, model parameterization or experimental design. Our results indicate that any rise in discrete-return height distributions as a consequence of increased pulse energy was overshadowed by the failure to detect treetops due to a reduction in discrete-return density at lower pulse repetition frequencies.

Ascending platform altitudes were associated with an upwards shift in discrete-return heights, particularly for height percentiles in the upper canopy $\left(\geq h_{75}\right)$. This upwards shift was primarily caused by the widening of laser beam diameters from $0.12-1.2 \mathrm{~m}$ as platform altitude increased from 400 to $1500 \mathrm{~m}$ (beam divergence $=0.3-0.8 \mathrm{mrad}$ ), resulting in a greater probability of pulses 
directly intercepting treetops as demonstrated empirically by Næsset [72] and Morsdorf et al. [63]. The widening of laser footprints at higher altitudes may also have been responsible for an increase in canopy cover and the proportion of multiple returns (Figure 8) as more biological material was intercepted in each laser footprint. These results contrasted with the empirical observations of Goodwin et al. [73] and Næsset [66] who recorded fewer multiple returns at higher platform altitudes due the attenuation of laser pulse energy across wider footprints. Despite this, our results highlighted the importance of selecting appropriate laser beam divergence thresholds when surveying forests at varying platform altitudes [245]. While the dispersal of laser beams at higher platform altitudes increases the probability of intersecting treetops with conical apices, pulses with narrower beam divergence (0.3-0.5 mrad) are often used for topographic mapping as narrow pulses penetrate closed-canopy forests to enable the acquisition of well-distributed ground returns [78]. Since ALS surveys are seldom undertaken specifically for forest inventory applications, further work is needed to investigate how beam divergence and platform altitude can be optimized to maximize the utility of ALS surveys for forest mensuration while simultaneously fulfilling the needs of other data users.

A potentially novel finding from our research is that longer pulse durations can trigger a decline in the proportion of multiple canopy returns as Gaussian waveform decomposition failed to resolve discrete-return signals from near-ground structures as half-pulse duration increased beyond $5 \mathrm{~ns}$. It is unclear whether the observed decline in multiple canopy returns was caused by: (i) reduced slant range resolution at longer pulse durations, or (ii) by echo-detection errors within the Gaussian waveform decomposition algorithm. However, these findings imply that the ability to modulate transmitted pulse durations may be useful when surveying: (i) closed-canopy forests where the acquisition of reliable ground returns is problematic [211,233], or (i) multi-layered forests where understory vegetation is only partially detected $[37,246]$. Unfortunately, this is seldom feasible in practice since transmitted pulse durations are often sensor-specific and non-adjustable. More significantly, our findings indicate that Gaussian waveform decomposition may be sub-optimal for near-ground echo detection, lending support to the development of alternative peak-detection methods capable of extracting near-ground laser returns for more detailed measurement of understory vegetation and ground surface topography $[247,248]$.

\section{Conclusions}

In this study, a variance-based global sensitivity analysis was undertaken to: (i) investigate how accurately the DART model was able to reproduce small-footprint ALS measurements acquired over commercial conifer plantations, and (ii) examine the impact of sensor and survey characteristics on the precision of discrete-return metrics commonly used for the derivation of forest inventory measurements. Our investigation demonstrated that DART could replicate small-footprint discrete-return metrics collected over 100 forest inventory plots dominated by Sitka spruce and Lodgepole pine with a high degree of accuracy and precision. These promising results demonstrated successful parameterization of the DART model for reproducing ALS data acquired by the RIEGL LMS-Q680i sensor in commercially important forests widespread throughout Britain and Ireland. Despite considerable modifications to survey settings and ground topography, the simulated discrete-return height distributions proved to be highly stable, indicating that discrete-return height metrics are potentially reliable predictor variables for the indirect retrieval of forest inventory biometrics across different ALS surveys. Conversely, ALS metrics such as discrete-return density, canopy cover and the proportion of multiple canopy returns were sensitive to variations in platform altitude, laser scanning angle, pulse repetition frequency and pulse duration. These latter findings indicate that canopy cover and density metrics are only comparable for discrete-return data collected under similar acquisition conditions, precluding their universal use for the derivation of forest inventory measurements across different ALS surveys.

Our study also highlighted some of the challenges and pitfalls of modeling complex forest canopies using synthetic three-dimensional trees generated from allometric relationships derived through manual field measurements. While our simulations replicated most ALS metrics with high 
fidelity, the proportion of multiple and ground returns was overestimated by $5.1 \%$ and $26.1 \%$ due to the misrepresentation of foliage. The accuracy of future simulations may therefore be improved by the importation of synthetic trees with biologically accurate shoot morphology, or the use of trees digitized directly from terrestrial laser scanning or photogrammetry. While our study successfully reproduced ALS measurements over structurally heterogeneous plantations, performing radiative transfer simulations over species-rich semi-natural forests remains a significant challenge for future research due to complexities associated with the replication of foliage morphology, density and orientation. Moreover, the parameterization of radiative transfer models such as DART requires considerable a priori knowledge of sensor specifications that is not always available for commercial ALS devices. Despite these caveats, we conclude that DART is a robust model for simulating discrete-return ALS measurements provided that realistic three-dimensional trees are imported into radiative transfer simulations.

Author Contributions: Conceptualization, O.R., P.B. and A.H.; Data curation, O.R. and D.M.; Formal analysis, O.R.; Investigation, O.R.; Methodology: O.R., Resources, D.M.; Software, O.R. and P.B.; Supervision, P.B. and A.H.; Writing-original draft, O.R.; Writing-review and editing, O.R., P.B., A.H. and D.M. All authors have read and agreed to the published version of the manuscript.

Funding: This research was funded through the Knowledge Economy Skills Scholarships (KESS2) initiative (kess2.ac.uk). KESS2 is a pan-Wales higher education initiative led by Bangor University and part-funded by the Welsh Government's European Social Fund (ESF) convergence programme for West Wales and the Valleys.

Acknowledgments: We kindly thank the forest managers and inventory personnel at Coillte Teoranta for providing the ALS data and field measurements used to calibrate the DART model. We are also grateful to Jean-Philippe Gastellu-Etchegorry and Tiangang Yin for their advice and support in using the DART model. Finally, SuperComputing Wales (www.supercomputing.wales) and Colin Sauze are thanked for supporting the project through the provision of a High-Performance Computing (HPC) facility on which most of the DART simulations were performed.

Conflicts of Interest: The authors declare no conflict of interest.

\section{Abbreviations}

The following abbreviations are used in this manuscript:

$\begin{array}{ll}\text { ALS } & \text { Airborne Laser Scanning } \\ \text { DART } & \text { The Discrete Anisotropic Radiative Transfer model } \\ \text { DBH } & \text { Tree diameter at breast height }(1.3 \mathrm{~m}) \\ \text { LiDAR } & \text { Light Detection and Ranging } \\ \text { MAPE } & \text { Mean Absolute Percentage Error } \\ \text { PRF } & \text { Pulse Repetition Frequency } \\ \text { RMSE } & \text { Root-Mean-Square Error }\end{array}$

\section{References}

1. McRoberts, R.E.; Tomppo, E.O. Remote sensing support for national forest inventories. Remote Sens. Environ. 2007, 110, 412-419. [CrossRef]

2. Barrett, F.; McRoberts, R.E.; Tomppo, E.; Cienciala, E.; Waser, L.T. A questionnaire-based review of the operational use of remotely sensed data by national forest inventories. Remote Sens. Environ. 2016, 174, 279-289. [CrossRef]

3. White, J.C.; Coops, N.C.; Wulder, M.A.; Vastaranta, M.; Hilker, T.; Tompalski, P. Remote sensing technologies for enhancing forest inventories: A review. Can. J. Remote Sens. 2016, 42, 619-641. [CrossRef]

4. Hyyppä, J.; Hyyppä, H.; Leckie, D.; Gougeon, F.; Yu, X.; Maltamo, M. Review of methods of small-footprint airborne laser scanning for extracting forest inventory data in boreal forests. Int. J. Remote Sens. 2008, 29, 1339-1366. [CrossRef]

5. Montaghi, A.; Corona, P.; Dalponte, M.; Gianelle, D.; Chirici, G.; Olsson, H. Airborne laser scanning of forest resources: An overview of research in Italy as a commentary case study. Int. J. Appl. Earth Obs. Geoinf. 2013, 23, 288-300. [CrossRef] 
6. Næsset, E. Area-based inventory in Norway-From innovation to an operational reality. In Forestry Applications of Airborne Laser Scanning; Springer: Berlin/Heidelberg, Germany, 2014; pp. 215-240.

7. Nilsson, M.; Nordkvist, K.; Jonzén, J.; Lindgren, N.; Axensten, P.; Wallerman, J.; Egberth, M.; Larsson, S.; Nilsson, L.; Eriksson, J.; et al. A nationwide forest attribute map of Sweden predicted using airborne laser scanning data and field data from the National Forest Inventory. Remote Sens. Environ. 2017, 194, 447-454. [CrossRef]

8. Naesset, E. Determination of mean tree height of forest stands using airborne laser scanner data. ISPRS J. Photogramm. Remote Sens. 1997, 52, 49-56. [CrossRef]

9. Means, J.E.; Acker, S.A.; Harding, D.J.; Blair, J.B.; Lefsky, M.A.; Cohen, W.B.; Harmon, M.E.; McKee, W.A. Use of large-footprint scanning airborne lidar to estimate forest stand characteristics in the Western Cascades of Oregon. Remote Sens. Environ. 1999, 67, 298-308. [CrossRef]

10. Andersen, H.E.; Reutebuch, S.E.; McGaughey, R.J. A rigorous assessment of tree height measurements obtained using airborne lidar and conventional field methods. Can. J. Remote Sens. 2006, 32, 355-366. [CrossRef]

11. Gobakken, T.; Næsset, E. Estimation of diameter and basal area distributions in coniferous forest by means of airborne laser scanner data. Scand. J. For. Res. 2004, 19, 529-542. [CrossRef]

12. Salas, C.; Ene, L.; Gregoire, T.G.; Næsset, E.; Gobakken, T. Modelling tree diameter from airborne laser scanning derived variables: A comparison of spatial statistical models. Remote Sens. Environ. 2010, 114, 1277-1285. [CrossRef]

13. Korhonen, L.; Korpela, I.; Heiskanen, J.; Maltamo, M. Airborne discrete-return LIDAR data in the estimation of vertical canopy cover, angular canopy closure and leaf area index. Remote Sens. Environ. 2011, 115, 1065-1080. [CrossRef]

14. Armston, J.; Disney, M.; Lewis, P.; Scarth, P.; Phinn, S.; Lucas, R.; Bunting, P.; Goodwin, N. Direct retrieval of canopy gap probability using airborne waveform lidar. Remote Sens. Environ. 2013, 134, 24-38. [CrossRef]

15. Peduzzi, A.; Wynne, R.H.; Fox, T.R.; Nelson, R.F.; Thomas, V.A. Estimating leaf area index in intensively managed pine plantations using airborne laser scanner data. For. Ecol. Manag. 2012, 270, 54-65. [CrossRef]

16. Pearse, G.D.; Morgenroth, J.; Watt, M.S.; Dash, J.P. Optimising prediction of forest leaf area index from discrete airborne lidar. Remote Sens. Environ. 2017, 200, 220-239. [CrossRef]

17. Holmgren, J.; Nilsson, M.; Olsson, H. Estimation of tree height and stem volume on plots using airborne laser scanning. For. Sci. 2003, 49, 419-428.

18. Hollaus, M.; Dorigo, W.; Wagner, W.; Schadauer, K.; Höfle, B.; Maier, B. Operational wide-area stem volume estimation based on airborne laser scanning and national forest inventory data. Int. J. Remote Sens. 2009, 30, 5159-5175. [CrossRef]

19. Popescu, S.C. Estimating biomass of individual pine trees using airborne lidar. Biomass Bioenergy 2007, 31, 646-655. [CrossRef]

20. Næsset, E.; Gobakken, T. Estimation of above-and below-ground biomass across regions of the boreal forest zone using airborne laser. Remote Sens. Environ. 2008, 112, 3079-3090. [CrossRef]

21. Patenaude, G.; Hill, R.; Milne, R.; Gaveau, D.; Briggs, B.; Dawson, T. Quantifying forest above ground carbon content using LiDAR remote sensing. Remote Sens. Environ. 2004, 93, 368-380. [CrossRef]

22. Asner, G.P.; Mascaro, J.; Muller-Landau, H.C.; Vieilledent, G.; Vaudry, R.; Rasamoelina, M.; Hall, J.S.; Van Breugel, M. A universal airborne LiDAR approach for tropical forest carbon mapping. Oecologia 2012, 168, 1147-1160. [CrossRef] [PubMed]

23. Van Leeuwen, M.; Nieuwenhuis, M. Retrieval of forest structural parameters using LiDAR remote sensing. Eur. J. For. Res. 2010, 129, 749-770. [CrossRef]

24. Yu, X.; Hyyppä, J.; Vastaranta, M.; Holopainen, M.; Viitala, R. Predicting individual tree attributes from airborne laser point clouds based on the random forests technique. ISPRS J. Photogramm. Remote Sens. 2011, 66, 28-37. [CrossRef]

25. Penner, M.; Pitt, D.; Woods, M. Parametric vs. nonparametric LiDAR models for operational forest inventory in boreal Ontario. Can. J. Remote Sens. 2013, 39, 426-443.

26. Brosofske, K.D.; Froese, R.E.; Falkowski, M.J.; Banskota, A. A review of methods for mapping and prediction of inventory attributes for operational forest management. For. Sci. 2014, 60, 733-756. [CrossRef] 
27. Xu, C.; Manley, B.; Morgenroth, J. Evaluation of modelling approaches in predicting forest volume and stand age for small-scale plantation forests in New Zealand with RapidEye and LiDAR. Int. J. Appl. Earth Obs. Geoinf. 2018, 73, 386-396. [CrossRef]

28. Boudreau, J.; Nelson, R.F.; Margolis, H.A.; Beaudoin, A.; Guindon, L.; Kimes, D.S. Regional aboveground forest biomass using airborne and spaceborne LiDAR in Québec. Remote Sens. Environ. 2008, 112, 3876-3890. [CrossRef]

29. Tsui, O.W.; Coops, N.C.; Wulder, M.A.; Marshall, P.L. Integrating airborne LiDAR and space-borne radar via multivariate kriging to estimate above-ground biomass. Remote Sens. Environ. 2013, 139, 340-352. [CrossRef]

30. Wilkes, P.; Jones, S.; Suarez, L.; Mellor, A.; Woodgate, W.; Soto-Berelov, M.; Haywood, A.; Skidmore, A. Mapping forest canopy height across large areas by upscaling ALS estimates with freely available satellite data. Remote Sens. 2015, 7, 12563-12587. [CrossRef]

31. Hudak, A.T.; Lefsky, M.A.; Cohen, W.B.; Berterretche, M. Integration of lidar and Landsat ETM+ data for estimating and mapping forest canopy height. Remote Sens. Environ. 2002, 82, 397-416. [CrossRef]

32. Asner, G.P. Tropical forest carbon assessment: Integrating satellite and airborne mapping approaches. Environ. Res. Lett. 2009, 4, 034009. [CrossRef]

33. Wulder, M.A.; White, J.C.; Nelson, R.F.; Næsset, E.; Ørka, H.O.; Coops, N.C.; Hilker, T.; Bater, C.W.; Gobakken, T. Lidar sampling for large-area forest characterization: A review. Remote. Sens. Environ. 2012, 121, 196-209. [CrossRef]

34. Xu, C.; Morgenroth, J.; Manley, B. Integrating data from discrete return airborne LiDAR and optical sensors to enhance the accuracy of forest description: A review. Curr. For. Rep. 2015, 1, 206-219. [CrossRef]

35. Wehr, A. LiDAR systems and calibration. In Topographic Laser Ranging and Scanning; CRC Press: Boca Raton, FL, USA, 2008; pp. 147-190.

36. Chasmer, L.; Hopkinson, C.; Treitz, P. Investigating laser pulse penetration through a conifer canopy by integrating airborne and terrestrial lidar. Can. J. Remote Sens. 2006, 32, 116-125. [CrossRef]

37. Hilker, T.; van Leeuwen, M.; Coops, N.C.; Wulder, M.A.; Newnham, G.J.; Jupp, D.L.; Culvenor, D.S. Comparing canopy metrics derived from terrestrial and airborne laser scanning in a Douglas-fir dominated forest stand. Trees 2010, 24, 819-832. [CrossRef]

38. Pirotti, F. Analysis of full-waveform LiDAR data for forestry applications: A review of investigations and methods. IForest-Biogeosci. For. 2011, 4, 100-106. [CrossRef]

39. Hancock, S.; Anderson, K.; Disney, M.; Gaston, K.J. Measurement of fine-spatial-resolution 3D vegetation structure with airborne waveform lidar: Calibration and validation with voxelised terrestrial lidar. Remote Sens. Environ. 2017, 188, 37-50. [CrossRef]

40. Wagner, W.; Ullrich, A.; Ducic, V.; Melzer, T.; Studnicka, N. Gaussian decomposition and calibration of a novel small-footprint full-waveform digitising airborne laser scanner. ISPRS J. Photogramm. Remote Sens. 2006, 60, 100-112. [CrossRef]

41. Reitberger, J.; Krzystek, P.; Stilla, U. Analysis of full waveform LIDAR data for the classification of deciduous and coniferous trees. Int. J. Remote Sens. 2008, 29, 1407-1431. [CrossRef]

42. Anderson, K.; Hancock, S.; Disney, M.; Gaston, K.J. Is waveform worth it? A comparison of LiDAR approaches for vegetation and landscape characterization. Remote Sens. Ecol. Conserv. 2016, 2, 5-15. [CrossRef]

43. Lindberg, E.; Olofsson, K.; Holmgren, J.; Olsson, H. Estimation of 3D vegetation structure from waveform and discrete return airborne laser scanning data. Remote Sens. Environ. 2012, 118, 151-161. [CrossRef]

44. Vaughn, N.R.; Moskal, L.M.; Turnblom, E.C. Tree species detection accuracies using discrete point lidar and airborne waveform lidar. Remote Sens. 2012, 4, 377-403. [CrossRef]

45. Sumnall, M.J.; Hill, R.A.; Hinsley, S.A. Comparison of small-footprint discrete return and full waveform airborne LiDAR data for estimating multiple forest variables. Remote Sens. Environ. 2016, 173, $214-223$. [CrossRef]

46. Brown, C.; Boyd, D.; Sjögersten, S.; Clewley, D.; Evers, S.; Aplin, P. Tropical peatland vegetation structure and biomass: Optimal exploitation of airborne laser scanning. Remote Sens. 2018, 10, 671. [CrossRef]

47. Corona, P.; Fattorini, L. Area-based lidar-assisted estimation of forest standing volume. Can. J. For. Res. 2008, 38, 2911-2916. [CrossRef] 
48. White, J.C.; Wulder, M.A.; Varhola, A.; Vastaranta, M.; Coops, N.C.; Cook, B.D.; Pitt, D.; Woods, M. A best practices guide for generating forest inventory attributes from airborne laser scanning data using an area-based approach. For. Chron. 2013, 89, 722-723. [CrossRef]

49. Hyyppa, J.; Kelle, O.; Lehikoinen, M.; Inkinen, M. A segmentation-based method to retrieve stem volume estimates from 3-D tree height models produced by laser scanners. IEEE Trans. Geosci. Remote Sens. 2001, 39, 969-975. [CrossRef]

50. Breidenbach, J.; Astrup, R. The semi-individual tree crown approach. In Forestry Applications of Airborne Laser Scanning; Springer: Berlin/Heidelberg, Germany, 2014; pp. 113-133.

51. Zhen, Z.; Quackenbush, L.; Zhang, L. Trends in automatic individual tree crown detection and delineation-Evolution of LiDAR data. Remote Sens. 2016, 8, 333. [CrossRef]

52. Næsset, E.; Gobakken, T. Estimating forest growth using canopy metrics derived from airborne laser scanner data. Remote Sens. Environ. 2005, 96, 453-465. [CrossRef]

53. Maltamo, M.; Eerikäinen, K.; Packalén, P.; Hyyppä, J. Estimation of stem volume using laser scanning-based canopy height metrics. Forestry 2006, 79, 217-229. [CrossRef]

54. Cao, L.; Coops, N.; Hermosilla, T.; Innes, J.; Dai, J.; She, G. Using small-footprint discrete and full-waveform airborne LiDAR metrics to estimate total biomass and biomass components in subtropical forests. Remote Sens. 2014, 6, 7110-7135. [CrossRef]

55. Bouvier, M.; Durrieu, S.; Fournier, R.A.; Renaud, J.P. Generalizing predictive models of forest inventory attributes using an area-based approach with airborne LiDAR data. Remote Sens. Environ. 2015, 156, 322-334. [CrossRef]

56. Maltamo, M.; Bollandsås, O.; Næsset, E.; Gobakken, T.; Packalén, P. Different plot selection strategies for field training data in ALS-assisted forest inventory. Forestry 2010, 84, 23-31. [CrossRef]

57. Dalponte, M.; Martinez, C.; Rodeghiero, M.; Gianelle, D. The role of ground reference data collection in the prediction of stem volume with LiDAR data in mountain areas. ISPRS J. Photogramm. Remote Sens. 2011, 66, 787-797. [CrossRef]

58. Ruiz, L.; Hermosilla, T.; Mauro, F.; Godino, M. Analysis of the influence of plot size and LiDAR density on forest structure attribute estimates. Forests 2014, 5, 936-951. [CrossRef]

59. Mauya, E.W.; Hansen, E.H.; Gobakken, T.; Bollandsås, O.M.; Malimbwi, R.E.; Næsset, E. Effects of field plot size on prediction accuracy of aboveground biomass in airborne laser scanning-assisted inventories in tropical rain forests of Tanzania. Carbon Balance Manag. 2015, 10, 10. [CrossRef] [PubMed]

60. Treitz, P.; Lim, K.; Woods, M.; Pitt, D.; Nesbitt, D.; Etheridge, D. LiDAR sampling density for forest resource inventories in Ontario, Canada. Remote Sens. 2012, 4, 830-848. [CrossRef]

61. Jakubowski, M.K.; Guo, Q.; Kelly, M. Tradeoffs between lidar pulse density and forest measurement accuracy. Remote Sens. Environ. 2013, 130, 245-253. [CrossRef]

62. Watt, M.S.; Meredith, A.; Watt, P.; Gunn, A. The influence of LiDAR pulse density on the precision of inventory metrics in young unthinned Douglas-fir stands during initial and subsequent LiDAR acquisitions. N. Z. J. For. Sci. 2014, 44, 18. [CrossRef]

63. Morsdorf, F.; Frey, O.; Meier, E.; Itten, K.I.; Allgöwer, B. Assessment of the influence of flying altitude and scan angle on biophysical vegetation products derived from airborne laser scanning. Int. J. Remote Sens. 2008, 29, 1387-1406. [CrossRef]

64. Tinkham, W.T.; Smith, A.M.; Hoffman, C.; Hudak, A.T.; Falkowski, M.J.; Swanson, M.E.; Gessler, P.E. Investigating the influence of LiDAR ground surface errors on the utility of derived forest inventories. Can. J. For. Res. 2012, 42, 413-422. [CrossRef]

65. Disney, M.I.; Kalogirou, V.; Lewis, P.; Prieto-Blanco, A.; Hancock, S.; Pfeifer, M. Simulating the impact of discrete-return lidar system and survey characteristics over young conifer and broadleaf forests. Remote Sens. Environ. 2010, 114, 1546-1560. [CrossRef]

66. Næsset, E. Effects of different sensors, flying altitudes, and pulse repetition frequencies on forest canopy metrics and biophysical stand properties derived from small-footprint airborne laser data. Remote Sens. Environ. 2009, 113, 148-159. [CrossRef]

67. Keränen, J.; Maltamo, M.; Packalen, P. Effect of flying altitude, scanning angle and scanning mode on the accuracy of ALS based forest inventory. Int. J. Appl. Earth Obs. Geoinf. 2016, 52, 349-360. [CrossRef] 
68. Næsset, E.; Bollandsås, O.M.; Gobakken, T. Comparing regression methods in estimation of biophysical properties of forest stands from two different inventories using laser scanner data. Remote Sens. Environ. 2005, 94, 541-553. [CrossRef]

69. Bater, C.W.; Wulder, M.A.; Coops, N.C.; Nelson, R.F.; Hilker, T.; Nasset, E. Stability of sample-based scanning-LiDAR-derived vegetation metrics for forest monitoring. IEEE Trans. Geosci. Remote Sens. 2011, 49, 2385-2392. [CrossRef]

70. Wallace, L.; Musk, R.; Lucieer, A. An assessment of the repeatability of automatic forest inventory metrics derived from UAV-borne laser scanning data. IEEE Trans. Geosci. Remote Sens. 2014, 52, 7160-7169. [CrossRef]

71. Hopkinson, C.; Chasmer, L.; Gynan, C.; Mahoney, C.; Sitar, M. Multisensor and multispectral lidar characterization and classification of a forest environment. Can. J. Remote Sens. 2016, 42, 501-520. [CrossRef]

72. Næsset, E. Effects of different flying altitudes on biophysical stand properties estimated from canopy height and density measured with a small-footprint airborne scanning laser. Remote. Sens. Environ. 2004, 91, 243-255. [CrossRef]

73. Goodwin, N.R.; Coops, N.C.; Culvenor, D.S. Assessment of forest structure with airborne LiDAR and the effects of platform altitude. Remote Sens. Environ. 2006, 103, 140-152. [CrossRef]

74. Chasmer, L.; Hopkinson, C.; Smith, B.; Treitz, P. Examining the influence of changing laser pulse repetition frequencies on conifer forest canopy returns. Photogramm. Eng. Remote Sens. 2006, 72, 1359-1367. [CrossRef]

75. Hopkinson, $\mathrm{C}$. The influence of flying altitude, beam divergence, and pulse repetition frequency on laser pulse return intensity and canopy frequency distribution. Can. J. Remote Sens. 2007, 33, 312-324. [CrossRef]

76. Zimble, D.A.; Evans, D.L.; Carlson, G.C.; Parker, R.C.; Grado, S.C.; Gerard, P.D. Characterizing vertical forest structure using small-footprint airborne LiDAR. Remote Sens. Environ. 2003, 87, 171-182. [CrossRef]

77. Yu, X.; Hyyppä, J.; Hyyppä, H.; Maltamo, M. Effects of flight altitude on tree height estimation using airborne laser scanning. In Proceedings of the Laser Scanners for Forest and Landscape Assessment-Instruments, Processing Methods and Applications, Freiburg, Germany, 3-6 October 2004; pp. 2-6.

78. Takahashi, T.; Awaya, Y.; Hirata, Y.; Furuya, N.; Sakai, T.; Sakai, A. Effects of flight altitude on LiDAR-derived tree heights in mountainous forests with poor laser penetration rates. Photogramm. J. Finl. 2008, 21, 86-96.

79. Montealegre, A.; Lamelas, M.; Riva, J. Interpolation routines assessment in ALS-derived digital elevation models for forestry applications. Remote Sens. 2015, 7, 8631-8654. [CrossRef]

80. Lim, K.; Hopkinson, C.; Treitz, P. Examining the effects of sampling point densities on laser canopy height and density metrics. For. Chron. 2008, 84, 876-885. [CrossRef]

81. Roussel, J.R.; Caspersen, J.; Béland, M.; Thomas, S.; Achim, A. Removing bias from LiDAR-based estimates of canopy height: Accounting for the effects of pulse density and footprint size. Remote Sens. Environ. 2017, 198, 1-16. [CrossRef]

82. Magnusson, M.; Fransson, J.E.; Holmgren, J. Effects on estimation accuracy of forest variables using different pulse density of laser data. For. Sci. 2007, 53, 619-626.

83. Gobakken, T.; Næsset, E. Assessing effects of laser point density, ground sampling intensity, and field sample plot size on biophysical stand properties derived from airborne laser scanner data. Can. J. For. Res. 2008, 38, 1095-1109. [CrossRef]

84. Thomas, V.; Treitz, P.; McCaughey, J.; Morrison, I. Mapping stand-level forest biophysical variables for a mixedwood boreal forest using lidar: An examination of scanning density. Can. J. For. Res. 2006, 36, 34-47. [CrossRef]

85. Zheng, G.; Ma, L.; Eitel, J.U.; He, W.; Magney, T.S.; Moskal, L.M.; Li, M. Retrieving directional gap fraction, extinction coefficient, and effective leaf area index by incorporating scan angle information from discrete aerial lidar data. IEEE Trans. Geosci. Remote Sens. 2016, 55, 577-590. [CrossRef]

86. Liu, J.; Skidmore, A.K.; Jones, S.; Wang, T.; Heurich, M.; Zhu, X.; Shi, Y. Large off-nadir scan angle of airborne LiDAR can severely affect the estimates of forest structure metrics. ISPRS J. Photogramm. Remote Sens. 2018, 136, 13-25. [CrossRef]

87. North, P.; Rosette, J.; Suárez, J.; Los, S. A Monte Carlo radiative transfer model of satellite waveform LiDAR. Int. J. Remote Sens. 2010, 31, 1343-1358. [CrossRef]

88. Hovi, A.; Korpela, I. Real and simulated waveform-recording LiDAR data in juvenile boreal forest vegetation. Remote Sens. Environ. 2014, 140, 665-678. [CrossRef]

89. Disney, M.; Lewis, P.; North, P. Monte Carlo ray tracing in optical canopy reflectance modelling. Remote Sens. Rev. 2000, 18, 163-196. [CrossRef] 
90. Morsdorf, F.; Nichol, C.; Malthus, T.; Woodhouse, I.H. Assessing forest structural and physiological information content of multi-spectral LiDAR waveforms by radiative transfer modelling. Remote Sens. Environ. 2009, 113, 2152-2163. [CrossRef]

91. Rosette, J.; North, P.; Suarez, J.; Los, S. Uncertainty within satellite LiDAR estimations of vegetation and topography. Int. J. Remote Sens. 2010, 31, 1325-1342. [CrossRef]

92. Hancock, S.; Disney, M.; Muller, J.P.; Lewis, P.; Foster, M. A threshold insensitive method for locating the forest canopy top with waveform lidar. Remote Sens. Environ. 2011, 115, 3286-3297. [CrossRef]

93. Rosette, J.; North, P.R.; Rubio-Gil, J.; Cook, B.; Los, S.; Suarez, J.; Sun, G.; Ranson, J.; Blair, J.B. Evaluating prospects for improved forest parameter retrieval from satellite LiDAR using a physically-based radiative transfer model. IEEE J. Sel. Top. Appl. Earth Obs. Remote Sens. 2013, 6, 45-53. [CrossRef]

94. Koetz, B.; Morsdorf, F.; Sun, G.; Ranson, K.J.; Itten, K.; Allgower, B. Inversion of a lidar waveform model for forest biophysical parameter estimation. IEEE Geosci. Remote Sens. Lett. 2006, 3, 49-53. [CrossRef]

95. Ma, H.; Song, J.; Wang, J. Forest canopy LAI and vertical FAVD profile inversion from airborne full-waveform LiDAR data based on a radiative transfer model. Remote Sens. 2015, 7, 1897-1914. [CrossRef]

96. Detto, M.; Asner, G.P.; Muller-Landau, H.C.; Sonnentag, O. Spatial variability in tropical forest leaf area density from multireturn lidar and modeling. J. Geophys. Res. Biogeosci. 2015, 120, 294-309. [CrossRef]

97. Bye, I.; North, P.R.; Los, S.; Kljun, N.; Rosette, J.; Hopkinson, C.; Chasmer, L.; Mahoney, C. Estimating forest canopy parameters from satellite waveform LiDAR by inversion of the FLIGHT three-dimensional radiative transfer model. Remote Sens. Environ. 2017, 188, 177-189. [CrossRef]

98. Calders, K.; Lewis, P.; Disney, M.; Verbesselt, J.; Herold, M. Investigating assumptions of crown archetypes for modelling LiDAR returns. Remote Sens. Environ. 2013, 134, 39-49. [CrossRef]

99. Van Leeuwen, M.; Coops, N.C.; Hilker, T.; Wulder, M.A.; Newnham, G.J.; Culvenor, D.S. Automated reconstruction of tree and canopy structure for modeling the internal canopy radiation regime. Remote Sens. Environ. 2013, 136, 286-300. [CrossRef]

100. Widlowski, J.L.; Côté, J.F.; Béland, M. Abstract tree crowns in 3D radiative transfer models: Impact on simulated open-canopy reflectances. Remote Sens. Environ. 2014, 142, 155-175. [CrossRef]

101. Ligot, G.; Balandier, P.; Courbaud, B.; Claessens, H. Forest radiative transfer models: Which approach for which application? Can. J. For. Res. 2014, 44, 391-403. [CrossRef]

102. Côté, J.F.; Widlowski, J.L.; Fournier, R.A.; Verstraete, M.M. The structural and radiative consistency of three-dimensional tree reconstructions from terrestrial lidar. Remote Sens. Environ. 2009, 113, 1067-1081. [CrossRef]

103. Hancock, S.; Lewis, P.; Foster, M.; Disney, M.; Muller, J.P. Measuring forests with dual wavelength lidar: A simulation study over topography. Agric. For. Meteorol. 2012, 161, 123-133. [CrossRef]

104. Montesano, P.; Rosette, J.; Sun, G.; North, P.; Nelson, R.; Dubayah, R.; Ranson, K.; Kharuk, V. The uncertainty of biomass estimates from modeled ICESat-2 returns across a boreal forest gradient. Remote Sens. Environ. 2015, 158, 95-109. [CrossRef]

105. Ni-Meister, W.; Yang, W.; Lee, S.; Strahler, A.H.; Zhao, F. Validating modeled lidar waveforms in forest canopies with airborne laser scanning data. Remote Sens. Environ. 2018, 204, 229-243. [CrossRef]

106. Holmgren, J.; Nilsson, M.; Olsson, H. Simulating the effects of lidar scanning angle for estimation of mean tree height and canopy closure. Can. J. Remote Sens. 2003, 29, 623-632. [CrossRef]

107. Lovell, J.; Jupp, D.; Newnham, G.; Coops, N.; Culvenor, D. Simulation study for finding optimal lidar acquisition parameters for forest height retrieval. For. Ecol. Manag. 2005, 214, 398-412. [CrossRef]

108. Goodwin, N.; Coops, N.; Culvenor, D. Development of a simulation model to predict LiDAR interception in forested environments. Remote Sens. Environ. 2007, 111, 481-492. [CrossRef]

109. Barton, C.V.M.; North, P. Remote sensing of canopy light use efficiency using the photochemical reflectance index: Model and sensitivity analysis. Remote Sens. Environ. 2001, 78, 264-273. [CrossRef]

110. Qin, H.; Wang, C.; Xi, X.; Tian, J.; Zhou, G. Simulating the Effects of the Airborne Lidar Scanning Angle, Flying Altitude, and Pulse Density for Forest Foliage Profile Retrieval. Appl. Sci. 2017, 7, 712. [CrossRef]

111. Saltelli, A.; Annoni, P. How to avoid a perfunctory sensitivity analysis. Environ. Model. Softw. 2010, 25, 1508-1517. [CrossRef]

112. Razavi, S.; Gupta, H.V. What do we mean by sensitivity analysis? The need for comprehensive characterization of "global" sensitivity in Earth and Environmental systems models. Water Resour. Res. 2015, 51, 3070-3092. [CrossRef] 
113. Saltelli, A.; Aleksankina, K.; Becker, W.; Fennell, P.; Ferretti, F.; Holst, N.; Li, S.; Wu, Q. Why so many published sensitivity analyses are false: A systematic review of sensitivity analysis practices. Environ. Model. Softw. 2019, 114, 29-39. [CrossRef]

114. Govaerts, Y.M.; Verstraete, M.M. Raytran: A Monte Carlo ray-tracing model to compute light scattering in three-dimensional heterogeneous media. IEEE Trans. Geosci. Remote Sens. 1998, 36, 493-505. [CrossRef]

115. Sun, G.; Ranson, K.J. Modeling lidar returns from forest canopies. IEEE Trans. Geosci. Remote Sens. 2000, $38,2617-2626$.

116. Ni-Meister, W.; Jupp, D.L.; Dubayah, R. Modeling lidar waveforms in heterogeneous and discrete canopies. IEEE Trans. Geosci. Remote Sens. 2001, 39, 1943-1958. [CrossRef]

117. Frazer, G.; Magnussen, S.; Wulder, M.; Niemann, K. Simulated impact of sample plot size and co-registration error on the accuracy and uncertainty of LiDAR-derived estimates of forest stand biomass. Remote Sens. Environ. 2011, 115, 636-649. [CrossRef]

118. Da Silva, D.; Balandier, P.; Boudon, F.; Marquier, A.; Godin, C. Modeling of light transmission under heterogeneous forest canopy: An appraisal of the effect of the precision level of crown description. Ann. For. Sci. 2012, 69, 181-193. [CrossRef]

119. Perot, T.; Mårell, A.; Korboulewsky, N.; Seigner, V.; Balandier, P. Modeling and predicting solar radiation transmittance in mixed forests at a within-stand scale from tree species basal area. For. Ecol. Manag. 2017, 390, 127-136. [CrossRef]

120. Kim, H.S.; Palmroth, S.; Thérézien, M.; Stenberg, P.; Oren, R. Analysis of the sensitivity of absorbed light and incident light profile to various canopy architecture and stand conditions. Tree Physiol. 2011, 31, 30-47. [CrossRef]

121. Romanczyk, P.; van Aardt, J.; Cawse-Nicholson, K.; Kelbe, D.; McGlinchy, J.; Krause, K. Assessing the impact of broadleaf tree structure on airborne full-waveform small-footprint LiDAR signals through simulation. Can. J. Remote Sens. 2013, 39, S60-S72. [CrossRef]

122. Schneider, F.D.; Leiterer, R.; Morsdorf, F.; Gastellu-Etchegorry, J.P.; Lauret, N.; Pfeifer, N.; Schaepman, M.E. Simulating imaging spectrometer data: 3D forest modeling based on LiDAR and in situ data. Remote Sens. Environ. 2014, 152, 235-250. [CrossRef]

123. Côté, J.F.; Fournier, R.A.; Frazer, G.W.; Niemann, K.O. A fine-scale architectural model of trees to enhance LiDAR-derived measurements of forest canopy structure. Agric. For. Meteorol. 2012, 166, 72-85. [CrossRef]

124. Calders, K.; Origo, N.; Burt, A.; Disney, M.; Nightingale, J.; Raumonen, P.; Åkerblom, M.; Malhi, Y.; Lewis, P. Realistic forest stand reconstruction from terrestrial LiDAR for radiative transfer modelling. Remote Sens. 2018, 10, 933. [CrossRef]

125. Saltelli, A.; Ratto, M.; Andres, T.; Campolongo, F.; Cariboni, J.; Gatelli, D.; Saisana, M.; Tarantola, S. Global Sensitivity Analysis: The Primer; John Wiley \& Sons: Hoboken, NJ, USA , 2008.

126. Petropoulos, G.; Srivastava, P.K. Sensitivity Analysis in Earth Observation Modelling; Elsevier: Amsterdam, The Netherlands, 2016.

127. Wallace, L.; Lucieer, A.; Watson, C.; Turner, D. Development of a UAV-LiDAR system with application to forest inventory. Remote Sens. 2012, 4, 1519-1543. [CrossRef]

128. Brede, B.; Lau, A.; Bartholomeus, H.; Kooistra, L. Comparing RIEGL RiCOPTER UAV LiDAR derived canopy height and DBH with terrestrial LiDAR. Sensors 2017, 17, 2371. [CrossRef] [PubMed]

129. Pulliainen, J.; Salminen, M.; Heinilä, K.; Cohen, J.; Hannula, H.R. Semi-empirical modeling of the scene reflectance of snow-covered boreal forest: Validation with airborne spectrometer and LIDAR observations. Remote Sens. Environ. 2014, 155, 303-311. [CrossRef]

130. Koukal, T.; Atzberger, C.; Schneider, W. Evaluation of semi-empirical BRDF models inverted against multi-angle data from a digital airborne frame camera for enhancing forest type classification. Remote Sens. Environ. 2014, 151, 27-43. [CrossRef]

131. Pisek, J.; Rautiainen, M.; Nikopensius, M.; Raabe, K. Estimation of seasonal dynamics of understory NDVI in northern forests using MODIS BRDF data: Semi-empirical versus physically-based approach. Remote Sens. Environ. 2015, 163, 42-47. [CrossRef]

132. Li, X.; Strahler, A.H. Geometric-optical bidirectional reflectance modeling of the discrete crown vegetation canopy: Effect of crown shape and mutual shadowing. IEEE Trans. Geosci. Remote Sens. 1992, 30, $276-292$. [CrossRef] 
133. Chen, J.M.; Leblanc, S.G. A four-scale bidirectional reflectance model based on canopy architecture. IEEE Trans. Geosci. Remote Sens. 1997, 35, 1316-1337. [CrossRef]

134. Gerard, F.; North, P. Analyzing the effect of structural variability and canopy gaps on forest BRDF using a geometric-optical model. Remote Sens. Environ. 1997, 62, 46-62. [CrossRef]

135. Jacquemoud, S.; Verhoef, W.; Baret, F.; Bacour, C.; Zarco-Tejada, P.J.; Asner, G.P.; François, C.; Ustin, S.L. PROSPECT + SAIL models: A review of use for vegetation characterization. Remote Sens. Environ. 2009, 113, S56-S66. [CrossRef]

136. Goel, N.S.; Thompson, R.L. A snapshot of canopy reflectance models and a universal model for the radiation regime. Remote Sens. Rev. 2000, 18, 197-225. [CrossRef]

137. Gastellu-Etchegorry, J.P.; Yin, T.; Lauret, N.; Cajgfinger, T.; Gregoire, T.; Grau, E.; Feret, J.B.; Lopes, M.; Guilleux, J.; Dedieu, G.; et al. Discrete anisotropic radiative transfer (DART 5) for modeling airborne and satellite spectroradiometer and LIDAR acquisitions of natural and urban landscapes. Remote Sens. 2015, 7, 1667-1701. [CrossRef]

138. Myneni, R.; Asrar, G.; Kanemasu, E. Light scattering in plant canopies: The method of successive orders of scattering approximations (SOSA). Agric. For. Meteorol. 1987, 39, 1-12. [CrossRef]

139. Borel, C.C.; Gerstl, S.A.; Powers, B.J. The radiosity method in optical remote sensing of structured 3-D surfaces. Remote Sens. Environ. 1991, 36, 13-44. [CrossRef]

140. Qin, W.; Gerstl, S.A. 3-D scene modeling of semidesert vegetation cover and its radiation regime. Remote Sens. Environ. 2000, 74, 145-162. [CrossRef]

141. Gerstl, S.A.; Zardecki, A. Discrete-ordinates finite-element method for atmospheric radiative transfer and remote sensing. Appl. Opt. 1985, 24, 81-93. [CrossRef]

142. Privette, J.; Myneni, R.; Tucker, C.; Emery, W. Invertibility of a 1-D discrete ordinates canopy reflectance model. Remote Sens. Environ. 1994, 48, 89-105. [CrossRef]

143. Verhoef, W.; Jia, L.; Xiao, Q.; Su, Z. Unified optical-thermal four-stream radiative transfer theory for homogeneous vegetation canopies. IEEE Trans. Geosci. Remote Sens. 2007, 45, 1808-1822. [CrossRef]

144. Leblanc, S.G.; Chen, J.M. A windows graphic user interface (GUI) for the five-scale model for fast BRDF simulations. Remote Sens. Rev. 2000, 19, 293-305. [CrossRef]

145. Peddle, D.R.; Johnson, R.L.; Cihlar, J.; Latifovic, R. Large area forest classification and biophysical parameter estimation using the 5-Scale canopy reflectance model in Multiple-Forward-Mode. Remote Sens. Environ. 2004, 89, 252-263. [CrossRef]

146. North, P.R. Three-dimensional forest light interaction model using a Monte Carlo method. IEEE Trans. Geosci. Remote Sens. 1996, 34, 946-956. [CrossRef]

147. Lewis, P. Three-dimensional plant modelling for remote sensing simulation studies using the Botanical Plant Modelling System. Agronomie 1999, 19, 185-210. [CrossRef]

148. Disney, M.; Lewis, P.; Saich, P. 3D modelling of forest canopy structure for remote sensing simulations in the optical and microwave domains. Remote Sens. Environ. 2006, 100, 114-132. [CrossRef]

149. Kobayashi, H.; Iwabuchi, H. A coupled 1-D atmosphere and 3-D canopy radiative transfer model for canopy reflectance, light environment, and photosynthesis simulation in a heterogeneous landscape. Remote Sens. Environ. 2008, 112, 173-185. [CrossRef]

150. Liu, D.; Sun, G.; Guo, Z.; Ranson, K.J.; Du, Y. Three-dimensional coherent radar backscatter model and simulations of scattering phase center of forest canopies. IEEE Trans. Geosci. Remote Sens. 2009, 48, 349-357.

151. Gastellu-Etchegorry, J.P.; Demarez, V.; Pinel, V.; Zagolski, F. Modeling radiative transfer in heterogeneous 3-D vegetation canopies. Remote Sens. Environ. 1996, 58, 131-156. [CrossRef]

152. Gastellu-Etchegorry, J.; Martin, E.; Gascon, F. DART: A 3D model for simulating satellite images and studying surface radiation budget. Int. J. Remote Sens. 2004, 25, 73-96. [CrossRef]

153. Grau, E.; Gastellu-Etchegorry, J.P. Radiative transfer modeling in the Earth-Atmosphere system with DART model. Remote Sens. Environ. 2013, 139, 149-170. [CrossRef]

154. Gascon, F.; Gastellu-Etchegorry, J.P.; Lefevre-Fonollosa, M.J.; Dufrene, E. Retrieval of forest biophysical variables by inverting a 3-D radiative transfer model and using high and very high resolution imagery. Int. J. Remote Sens. 2004, 25, 5601-5616. [CrossRef]

155. Sepulcre-Canto, G.; Zarco-Tejada, P.J.; Sobrino, J.; Berni, J.A.; Jimenez-Munoz, J.; Gastellu-Etchegorry, J.P. Discriminating irrigated and rainfed olive orchards with thermal ASTER imagery and DART 3D simulation. Agric. For. Meteorol. 2009, 149, 962-975. [CrossRef] 
156. Hernández-Clemente, R.; Navarro-Cerrillo, R.M.; Zarco-Tejada, P.J. Carotenoid content estimation in a heterogeneous conifer forest using narrow-band indices and PROSPECT+ DART simulations. Remote Sens. Environ. 2012, 127, 298-315. [CrossRef]

157. Banskota, A.; Wynne, R.; Thomas, V.; Serbin, S.; Kayastha, N.; Gastellu-Etchegorry, J.; Townsend, P. Investigating the utility of wavelet transforms for inverting a 3-D radiative transfer model using hyperspectral data to retrieve forest LAI. Remote Sens. 2013, 5, 2639-2659. [CrossRef]

158. Malenovskỳ, Z.; Homolová, L.; Zurita-Milla, R.; Lukeš, P.; Kaplan, V.; Hanuš, J.; Gastellu-Etchegorry, J.P.; Schaepman, M.E. Retrieval of spruce leaf chlorophyll content from airborne image data using continuum removal and radiative transfer. Remote Sens. Environ. 2013, 131, 85-102. [CrossRef]

159. de Castro Oliveira, J.; Féret, J.B.; Ponzoni, F.J.; Nouvellon, Y.; Gastellu-Etchegorry, J.P.; Campoe, O.C.; Stape, J.L.; Rodriguez, L.C.E.; Le Maire, G. Simulating the canopy reflectance of different eucalypt genotypes with the DART 3-D model. IEEE J. Sel. Top. Appl. Earth Obs. Remote Sens. 2017, 10, 4844-4852. [CrossRef]

160. Ferreira, M.P.; Féret, J.B.; Grau, E.; Gastellu-Etchegorry, J.P.; Shimabukuro, Y.E.; de Souza Filho, C.R. Retrieving structural and chemical properties of individual tree crowns in a highly diverse tropical forest with 3D radiative transfer modeling and imaging spectroscopy. Remote Sens. Environ. 2018, 211, $276-291$. [CrossRef]

161. Gascon, F.; Gastellu-Etchegorry, J.P.; Lefèvre, M.J. Radiative transfer model for simulating high-resolution satellite images. IEEE Trans. Geosci. Remote Sens. 2001, 39, 1922-1926. [CrossRef]

162. Malenovskỳ, Z.; Martin, E.; Homolová, L.; Gastellu-Etchegorry, J.P.; Zurita-Milla, R.; Schaepman, M.E.; Pokornỳ, R.; Clevers, J.G.; Cudlín, P. Influence of woody elements of a Norway spruce canopy on nadir reflectance simulated by the DART model at very high spatial resolution. Remote Sens. Environ. 2008, 112, 1-18. [CrossRef]

163. Yin, T.; Lauret, N.; Gastellu-Etchegorry, J.P. Simulating images of passive sensors with finite field of view by coupling 3-D radiative transfer model and sensor perspective projection. Remote Sens. Environ. 2015, 162, 169-185. [CrossRef]

164. Gastellu-Etchegorry, J.; Guillevic, P.; Zagolski, F.; Demarez, V.; Trichon, V.; Deering, D.; Leroy, M. Modeling BRF and radiation regime of boreal and tropical forests: I. BRF. Remote Sens. Environ. 1999, 68, 281-316. [CrossRef]

165. Pinty, B.; Gobron, N.; Widlowski, J.L.; Gerstl, S.A.; Verstraete, M.M.; Antunes, M.; Bacour, C.; Gascon, F.; Gastellu, J.P.; Goel, N.; et al. Radiation transfer model intercomparison (RAMI) exercise. J. Geophys. Res. Atmos. 2001, 106, 11937-11956. [CrossRef]

166. Pinty, B.; Widlowski, J.L.; Taberner, M.; Gobron, N.; Verstraete, M.; Disney, M.; Gascon, F.; Gastellu, J.P.; Jiang, L.; Kuusk, A.; et al. Radiation Transfer Model Intercomparison (RAMI) exercise: Results from the second phase. J. Geophys. Res. Atmos. 2004, 109. [CrossRef]

167. Widlowski, J.L.; Taberner, M.; Pinty, B.; Bruniquel-Pinel, V.; Disney, M.; Fernandes, R.; Gastellu-Etchegorry, J.P.; Gobron, N.; Kuusk, A.; Lavergne, T.; et al. Third Radiation Transfer Model Intercomparison (RAMI) exercise: Documenting progress in canopy reflectance models. J. Geophys. Res. Atmos. 2007, 112. [CrossRef]

168. Widlowski, J.L.; Pinty, B.; Lopatka, M.; Atzberger, C.; Buzica, D.; Chelle, M.; Disney, M.; Gastellu-Etchegorry, J.P.; Gerboles, M.; Gobron, N.; et al. The fourth radiation transfer model intercomparison (RAMI-IV): Proficiency testing of canopy reflectance models with ISO-13528. J. Geophys. Res. Atmos. 2013, 118, 6869-6890. [CrossRef]

169. Widlowski, J.L.; Mio, C.; Disney, M.; Adams, J.; Andredakis, I.; Atzberger, C.; Brennan, J.; Busetto, L.; Chelle, M.; Ceccherini, G.; et al. The fourth phase of the radiative transfer model intercomparison (RAMI) exercise: Actual canopy scenarios and conformity testing. Remote Sens. Environ. 2015, 169, 418-437. [CrossRef]

170. Hmida, S.B.; Kallel, A.; Gastellu-Etchegorry, J.P.; Roujean, J.L. Crop Biophysical Properties Estimation Based on LiDAR Full-Waveform Inversion Using the DART RTM. IEEE J. Sel. Top. Appl. Earth Obs. Remote Sens. 2017, 10, 4853-4868. [CrossRef]

171. Mkaouar, A.; Kallel, A.; Guidara, R.; Rabah, Z.B. Detection of forest strata volume using LiDAR data. In Proceedings of the 2018 4th International Conference on Advanced Technologies for Signal and Image Processing (ATSIP), Sousse, Tunisia, 22-24 March 2018; pp. 1-6. 
172. Grau, E.; Durrieu, S.; Fournier, R.; Gastellu-Etchegorry, J.P.; Yin, T. Estimation of 3D vegetation density with Terrestrial Laser Scanning data using voxels. A sensitivity analysis of influencing parameters. Remote Sens. Environ. 2017, 191, 373-388. [CrossRef]

173. Yin, T.; Gastellu-Etchegorry, J.P.; Grau, E.; Lauret, N.; Rubio, J. Simulating satellite waveform Lidar with DART model. In Proceedings of the 2013 IEEE International Geoscience and Remote Sensing Symposium-IGARSS, Melbourne, Australia, 21-26 July 2013; pp. 3029-3032.

174. Grau, E.; Durrieu, S.; Antin, C.; Debise, H.; Vincent, G.; Lavalley, C.; Bouvier, M. Modelling full waveform Lidar data on forest structures at plot level: A sensitivity analysis of forest and sensor main characteristics on full-waveform simulated data. In Proceedings of the SilviLaser 2015, La Grande-Motte, France, 28-30 September 2015; pp. 146-148.

175. Yin, T.; Gastellu-Etchegorry, J.P.; Norford, L.K. Recent advances of modeling lidar data using dart and radiometric calibration coefficient from LVIS waveforms comparison. In Proceedings of the 2017 IEEE International Geoscience and Remote Sensing Symposium (IGARSS), Fort Worth, TX, USA, 23-28 July 2017; pp. 1461-1464.

176. Yin, T.; Lauret, N.; Gastellu-Etchegorry, J.P. Simulation of satellite, airborne and terrestrial LiDAR with DART (II): ALS and TLS multi-pulse acquisitions, photon counting, and solar noise. Remote Sens. Environ. 2016, 184, 454-468. [CrossRef]

177. Bunting, P.; Armston, J.; Lucas, R.M.; Clewley, D. Sorted pulse data (SPD) library. Part I: A generic file format for LiDAR data from pulsed laser systems in terrestrial environments. Comput. Geosci. 2013, 56, 197-206. [CrossRef]

178. Gastellu-Etchegorry, J.P.; Yin, T.; Lauret, N.; Grau, E.; Rubio, J.; Cook, B.D.; Morton, D.C.; Sun, G. Simulation of satellite, airborne and terrestrial LiDAR with DART (I): Waveform simulation with quasi-Monte Carlo ray tracing. Remote Sens. Environ. 2016, 184, 418-435. [CrossRef]

179. Yin, T.; Rubio, J.; Gastellu-Etchegorry, J.P.; Grau, E.; Lauret, N. Direction discretization for radiative transfer modeling: An introduction to the new direction model of dart. In Proceedings of the 2012 IEEE International Geoscience and Remote Sensing Symposium, Munich, Germany, 22-27 July 2012; pp. 5069-5072.

180. Yin, T.; Gastellu-Etchegorry, J.P.; Lauret, N.; Grau, E.; Rubio, J. A new approach of direction discretization and oversampling for 3D anisotropic radiative transfer modeling. Remote Sens. Environ. 2013, 135, $213-223$. [CrossRef]

181. Lathrop, K.D. Ray effects in discrete ordinates equations. Nucl. Sci. Eng. 1968, 32, 357-369. [CrossRef]

182. Chai, J.C.; Lee, H.S.; Patankar, S.V. Ray effect and false scattering in the discrete ordinates method. Numer. Heat Transf. Part B Fundam. 1993, 24, 373-389. [CrossRef]

183. Lintermann, B.; Deussen, O. Interactive modeling of plants. IEEE Comput. Graph. Appl. 1999, 19, 56-65. [CrossRef]

184. Griffon, S.; De Coligny, F. AMAPstudio: An editing and simulation software suite for plants architecture modelling. Ecol. Model. 2014, 290, 3-10. [CrossRef]

185. Yáñez, L.; Homolová, L.; Malenovskỳ, Z.; Schaepman, M. Geometrical and structural parameterization of forest canopy radiative transfer by LiDAR measurements. In Proceedings of the 21th ISPRS Congrress, Beijing, China, 3-11 July 2008; pp. 45-50.

186. Roberts, G.; Wooster, M.; Lauret, N.; Gastellu-Etchegorry, J.P.; Lynham, T.; McRae, D. Investigating the impact of overlying vegetation canopy structures on fire radiative power (FRP) retrieval through simulation and measurement. Remote Sens. Environ. 2018, 217, 158-171. [CrossRef]

187. Janoutová, R.; Homolová, L.; Malenovskỳ, Z.; Hanuš, J.; Lauret, N.; Gastellu-Etchegorry, J.P. Influence of 3D Spruce Tree Representation on Accuracy of Airborne and Satellite Forest Reflectance Simulated in DART. Forests 2019, 10, 292. [CrossRef]

188. Bunting, P.; Armston, J.; Clewley, D.; Lucas, R.M. Sorted pulse data (SPD) library-Part II: A processing framework for LiDAR data from pulsed laser systems in terrestrial environments. Comput. Geosci. 2013, 56, 207-215. [CrossRef]

189. Zhang, K.; Chen, S.C.; Whitman, D.; Shyu, M.L.; Yan, J.; Zhang, C. A progressive morphological filter for removing nonground measurements from airborne LIDAR data. IEEE Trans. Geosci. Remote Sens. 2003, 41, 872-882. [CrossRef] 
190. Evans, J.S.; Hudak, A.T. A multiscale curvature algorithm for classifying discrete return LiDAR in forested environments. IEEE Trans. Geosci. Remote Sens. 2007, 45, 1029-1038. [CrossRef]

191. Bater, C.W.; Coops, N.C. Evaluating error associated with lidar-derived DEM interpolation. Comput. Geosci. 2009, 35, 289-300. [CrossRef]

192. Onyx Computing. OnyxTree Modelling Software for Vegetation. 2017. Available online: www.onyxtree.com (accessed on 13 March 2019).

193. Norman, J.; Jarvis, P. Photosynthesis in Sitka spruce (Picea sitchensis (Bong.) Carr.). III. Measurements of canopy structure and interception of radiation. J. Appl. Ecol. 1974, 11, 375-398. [CrossRef]

194. Fonweban, J.; Gardiner, B.; Macdonald, E.; Auty, D. Taper functions for Scots pine (Pinus sylvestris L.) and Sitka spruce (Picea sitchensis (Bong.) Carr.) in northern Britain. Forestry 2011, 84, 49-60. [CrossRef]

195. Johnson, M.E.; Moore, L.M.; Ylvisaker, D. Minimax and maximin distance designs. J. Stat. Plan. Inference 1990, 26, 131-148. [CrossRef]

196. Helton, J.C.; Davis, F.J. Latin hypercube sampling and the propagation of uncertainty in analyses of complex systems. Reliab. Eng. Syst. Saf. 2003, 81, 23-69. [CrossRef]

197. Deutsch, J.L.; Deutsch, C.V. Latin hypercube sampling with multidimensional uniformity. J. Stat. Plan. Inference 2012, 142, 763-772. [CrossRef]

198. Dalponte, M.; Coomes, D.A. Tree-centric mapping of forest carbon density from airborne laser scanning and hyperspectral data. Methods Ecol. Evol. 2016, 7, 1236-1245. [CrossRef] [PubMed]

199. Zörner, J.; Dymond, J.; Shepherd, J.; Wiser, S.; Jolly, B. LiDAR-Based Regional Inventory of Tall Trees-Wellington, New Zealand. Forests 2018, 9, 702. [CrossRef]

200. Li, W.; Guo, Q.; Jakubowski, M.K.; Kelly, M. A new method for segmenting individual trees from the lidar point cloud. Photogramm. Eng. Remote Sens. 2012, 78, 75-84. [CrossRef]

201. Véga, C.; Hamrouni, A.; El Mokhtari, S.; Morel, J.; Bock, J.; Renaud, J.P.; Bouvier, M.; Durrieu, S. PTrees: A point-based approach to forest tree extraction from lidar data. Int. J. Appl. Earth Obs. Geoinf. 2014, 33, 98-108. [CrossRef]

202. RIEGL Laser Measurement Systems GmbH. LMS-Q680i: Long-Range Airborne Laser Scanner for Full Waveform Analysis. 2012. Available online: www.riegl.com/uploads/tx_pxpriegldownloads/10_ DataSheet_LMS-Q680i_28-09-2012_01.pdf (accessed on 28 November 2018).

203. Yin, T. (NASA Goddard Space Flight Center, Greenbelt, MD, USA). Personal communication, 2019.

204. Jalobeanu, A.; Gonçalves, G.R. The full-waveform LiDAR Riegl LMS-Q680i: From reverse engineering to sensor modeling. In Proceedings of the American Society of Photogrammetry and Remote Sensing Annual Conference, Sacramento, CA, USA, 19-23 March 2012.

205. Wehr, A.; Lohr, U. Airborne laser scanning-An introduction and overview. ISPRS J. Photogramm. Remote Sens. 1999, 54, 68-82. [CrossRef]

206. Baltsavias, E.P. Airborne laser scanning: Basic relations and formulas. ISPRS J. Photogramm. Remote Sens. 1999, 54, 199-214. [CrossRef]

207. Armston, J.D. Assessment of Airborne Lidar for Measuring the Structure of Forests and Woodlands in Queensland, Australia. Ph.D. Thesis, University of Queensland, Brisbane, Australia, 2013.

208. Armston, J.; Disney, M.; Lewis, P.; Scarth, P.; Bunting, P.; Lucas, R.; Phinn, S.; Goodwin, N. Comparison of discrete return and waveform airborne LiDAR derived estimates of fractional cover in an Australian savanna. In Proceedings of the SilviLaser 2011, Hobart, Australia, 16-20 October 2011.

209. Mongus, D.; Žalik, B. Parameter-free ground filtering of LiDAR data for automatic DTM generation. ISPRS J. Photogramm. Remote Sens. 2012, 67, 1-12. [CrossRef]

210. Tange, O. GNU parallel-The command-line power tool. USENIX Mag. 2011, 36, $42-47$.

211. Takahashi, T.; Yamamoto, K.; Miyachi, Y.; Senda, Y.; Tsuzuku, M. The penetration rate of laser pulses transmitted from a small-footprint airborne LiDAR: A case study in closed canopy, middle-aged pure sugi (Cryptomeria japonica D. Don) and hinoki cypress (Chamaecyparis obtusa Sieb. et Zucc.) stands in Japan. J. For. Res. 2006, 11, 117-123. [CrossRef]

212. Morsdorf, F.; Kötz, B.; Meier, E.; Itten, K.; Allgöwer, B. Estimation of LAI and fractional cover from small footprint airborne laser scanning data based on gap fraction. Remote Sens. Environ. 2006, 104, 50-61. [CrossRef]

213. Heiskanen, J.; Korhonen, L.; Hietanen, J.; Pellikka, P.K. Use of airborne lidar for estimating canopy gap fraction and leaf area index of tropical montane forests. Int. J. Remote Sens. 2015, 36, 2569-2583. [CrossRef] 
214. Korhonen, L.; Korhonen, K.T.; Rautiainen, M.; Stenberg, P. Estimation of Forest Canopy Cover: A Comparison of Field Measurement Techniques. Silva Fenn. 2006, 40, 4. [CrossRef]

215. Paletto, A.; Tosi, V. Forest canopy cover and canopy closure: Comparison of assessment techniques. Eur. J. For. Res. 2009, 128, 265-272. [CrossRef]

216. Lefsky, M.A.; Cohen, W.; Acker, S.; Parker, G.G.; Spies, T.; Harding, D. Lidar remote sensing of the canopy structure and biophysical properties of Douglas-fir western hemlock forests. Remote Sens. Environ. 1999, 70, 339-361. [CrossRef]

217. Zhang, Z.; Cao, L.; She, G. Estimating forest structural parameters using canopy metrics derived from airborne LiDAR data in subtropical forests. Remote Sens. 2017, 9, 940. [CrossRef]

218. Wu, X.; Shen, X.; Cao, L.; Wang, G.; Cao, F. Assessment of Individual Tree Detection and Canopy Cover Estimation using Unmanned Aerial Vehicle based Light Detection and Ranging (UAV-LiDAR) Data in Planted Forests. Remote Sens. 2019, 11, 908. [CrossRef]

219. Hansen, E.H.; Gobakken, T.; Næsset, E. Effects of pulse density on digital terrain models and canopy metrics using airborne laser scanning in a tropical rainforest. Remote Sens. 2015, 7, 8453-8468. [CrossRef]

220. Fisher, R.A. Statistical Methods for Research Workers; Oliver and Boyd: Edinburgh, UK, 1925.

221. Darling, D.A. The kolmogorov-smirnov, cramer-von mises tests. Ann. Math. Stat. 1957, $28,823-838$. [CrossRef]

222. Scholz, F.W.; Stephens, M.A. K-sample Anderson-Darling tests. J. Am. Stat. Assoc. 1987, 82, 918-924.

223. Engmann, S.; Cousineau, D. Comparing distributions: The two-sample Anderson-Darling test as an alternative to the Kolmogorov-Smirnoff test. J. Appl. Quant. Methods 2011, 6, 1-17.

224. Herman, J.; Usher, W. SALib: An open-source Python library for sensitivity analysis. J. Open Source Softw. 2017, 2, 97. [CrossRef]

225. Sobol, I.M. Sensitivity estimates for nonlinear mathematical models. Math. Model. Comput. Exp. 1993, 1, 407-414.

226. Sobol, I.M. Global sensitivity indices for nonlinear mathematical models and their Monte Carlo estimates. Math. Comput. Simul. 2001, 55, 271-280. [CrossRef]

227. Wan, H.; Xia, J.; Zhang, L.; She, D.; Xiao, Y.; Zou, L. Sensitivity and interaction analysis based on Sobol'method and its application in a distributed flood forecasting model. Water 2015, 7, 2924-2951. [CrossRef]

228. Homma, T.; Saltelli, A. Importance measures in global sensitivity analysis of nonlinear models. Reliab. Eng. Syst. Saf. 1996, 52, 1-17. [CrossRef]

229. Saltelli, A.; Annoni, P.; Azzini, I.; Campolongo, F.; Ratto, M.; Tarantola, S. Variance based sensitivity analysis of model output. Design and estimator for the total sensitivity index. Comput. Phys. Commun. 2010, 181, 259-270. [CrossRef]

230. Suárez, J.C.; Ontiveros, C.; Smith, S.; Snape, S. Use of airborne LiDAR and aerial photography in the estimation of individual tree heights in forestry. Comput. Geosci. 2005, 31, 253-262. [CrossRef]

231. Donoghue, D.; Watt, P. Using LiDAR to compare forest height estimates from IKONOS and Landsat ETM+ data in Sitka spruce plantation forests. Int. J. Remote Sens. 2006, 27, 2161-2175. [CrossRef]

232. Bragg, D.C. An improved tree height measurement technique tested on mature southern pines. South. J. Appl. For. 2008, 32, 38-43. [CrossRef]

233. Gatziolis, D.; Fried, J.S.; Monleon, V.S. Challenges to estimating tree height via LiDAR in closed-canopy forests: A parable from Western Oregon. For. Sci. 2010, 56, 139-155.

234. Conry, M.; Clinch, P. The effect of soil quality on the yield class of a range of forest species grown on the Slieve Bloom Mountain and foothills. For. Int. J. For. Res. 1989, 62, 397-408. [CrossRef]

235. McInerney, D.; Kempeneers, P.; Marron, M.; McRoberts, R.E. Analysis of broadleaf encroachment in coniferous forest plantations using multi-temporal satellite imagery. Int. J. Appl. Earth Obs. Geoinf. 2019, 78, 130-137. [CrossRef]

236. McInerney, D.; Barrett, F.; Landy, J.; McDonagh, M. A rapid assessment using remote sensing of windblow damage in Irish forests following Storm Darwin. Ir. For. 2016, 73, 161-179.

237. Smolander, S.; Stenberg, P. Simple parameterizations of the radiation budget of uniform broadleaved and coniferous canopies. Remote Sens. Environ. 2005, 94, 355-363. [CrossRef]

238. Rautiainen, M.; Stenberg, P. Application of photon recollision probability in coniferous canopy reflectance simulations. Remote Sens. Environ. 2005, 96, 98-107. [CrossRef] 
239. Rochdi, N.; Fernandes, R.; Chelle, M. An assessment of needles clumping within shoots when modeling radiative transfer within homogeneous canopies. Remote Sens. Environ. 2006, 102, 116-134. [CrossRef]

240. Weber, J.; Penn, J. Creation and rendering of realistic trees. In Proceedings of the 22nd Annual Conference on Computer Graphics and Interactive Techniques, Los Angeles, CA, USA, 6-11 August 1995; pp. 119-128.

241. Korpela, I.; Hovi, A.; Korhonen, L. Backscattering of individual LiDAR pulses from forest canopies explained by photogrammetrically derived vegetation structure. ISPRS J. Photogramm. Remote Sens. 2013, 83, 81-93. [CrossRef]

242. Hudak, A.T.; Strand, E.K.; Vierling, L.A.; Byrne, J.C.; Eitel, J.U.; Martinuzzi, S.; Falkowski, M.J. Quantifying aboveground forest carbon pools and fluxes from repeat LiDAR surveys. Remote Sens. Environ. 2012, 123, 25-40. [CrossRef]

243. Gopalakrishnan, R.; Thomas, V.; Coulston, J.; Wynne, R. Prediction of canopy heights over a large region using heterogeneous lidar datasets: Efficacy and challenges. Remote Sens. 2015, 7, 11036-11060. [CrossRef]

244. Sumnall, M.; Peduzzi, A.; Fox, T.R.; Wynne, R.H.; Thomas, V.A.; Cook, B. Assessing the transferability of statistical predictive models for leaf area index between two airborne discrete return LiDAR sensor designs within multiple intensely managed Loblolly pine forest locations in the south-eastern USA. Remote Sens. Environ. 2016, 176, 308-319. [CrossRef]

245. Evans, J.S.; Hudak, A.T.; Faux, R.; Smith, A.M.S. Discrete Return Lidar in Natural Resources: Recommendations for Project Planning, Data Processing, and Deliverables. Remote Sens. 2009, 1, 776-794. [CrossRef]

246. Hamraz, H.; Contreras, M.A.; Zhang, J. Vertical stratification of forest canopy for segmentation of understory trees within small-footprint airborne LiDAR point clouds. ISPRS J. Photogramm. Remote Sens. 2017, 130, 385-392. [CrossRef]

247. Chauve, A.; Vega, C.; Durrieu, S.; Bretar, F.; Allouis, T.; Pierrot Deseilligny, M.; Puech, W. Advanced full-waveform lidar data echo detection: Assessing quality of derived terrain and tree height models in an alpine coniferous forest. Int. J. Remote Sens. 2009, 30, 5211-5228. [CrossRef]

248. Korpela, I.; Hovi, A.; Morsdorf, F. Understory trees in airborne LiDAR data-Selective mapping due to transmission losses and echo-triggering mechanisms. Remote Sens. Environ. 2012, 119, 92-104. [CrossRef]

(C) 2020 by the authors. Licensee MDPI, Basel, Switzerland. This article is an open access article distributed under the terms and conditions of the Creative Commons Attribution (CC BY) license (http:/ / creativecommons.org/licenses/by/4.0/). 